\title{
DIAGÉNESIS ÓSEA EN EL BOSQUE CADUCIFOLIO DE PATAGONIA MERIDIONAL AL ESTE DE LOS ANDES: MODELO TEÓRICO Y EVIDENCIA EMPÍRICA
}

\author{
NATALIA S. MORALES ${ }^{a}$, GUSTAVO BARRIENTOS $^{\mathrm{b}} \&$ G. LORENA L'HEUREUX ${ }^{c}$

\section{RESUMEN}

En Patagonia meridional, el conocimiento acerca del modo de ocupación humana del bosque caducifolio de Nothofagus depende de una correcta apreciación del contenido y distribución de la evidencia material. En el caso de los restos óseos, existe incertidumbre acerca de los potenciales sesgos de preservación de los conjuntos enterrados en diferentes sectores del bosque. El objetivo de este trabajo es, por un lado, formular un modelo de diagénesis ósea basado en las propiedades físicas, químicas y biológicas de los suelos y, por el otro, evaluar algunas de sus implicancias con evidencia procedente del sitio a cielo abierto Cancha Carrera 1 (CC1) (Holoceno tardío, SO de la provincia de Santa Cruz, República Argentina). El modelo prevé un decrecimiento en el grado de preservación ósea en sentido este-oeste y en relación con la altitud, con un bajo potencial de preservación en suelos de los órdenes Espodosoles e Inceptisoles, intermedio en Andisoles y más alto en Entisoles y Molisoles. Los resultados del estudio macroscópico y microscópico de los huesos de guanaco (Lama guanicoe) recuperados en un probable molisol en CC1 se ajustan a tales expectativas, indicando que los principales factores de alteración lo constituyen la disolución mineral, la actividad bacteriana y, sobre todo, la acción de raíces.

PALABRAS CLAVE: Patagonia meridional, bosque caducifolio, suelos, diagénesis ósea, guanaco.

\section{BONE DIAGENESIS IN THE DECIDUOUS FOREST OF SOUTHERN PATAGONIA EAST OF THE ANDES: THEORETICAL MODEL AND EMPIRICAL EVIDENCE}

\begin{abstract}
In southern Patagonia, knowledge about the human occupation or exploitation of the deciduous forest of Nothofagus depends on a correct appreciation of the content and distribution of the material evidence. In the case of bone remains, there is uncertainty about the potential preservational biases of the assemblages either deposited or buried in different sectors of the forest. The objective of this paper is, on the one hand, to formulate a bone diagenesis model based on the physical, chemical and biological properties of soils and, on the other, to evaluate it with evidence from the open-air site Cancha Carrera

a División Antropología, FCNyM, UNLP; CONICET. Paseo del Bosque s/n. B1900FWA. La Plata, República Argentina. moralesnatalia@fcnym.unlp.edu.ar

b División Antropología, FCNyM, UNLP; CONICET. Paseo del Bosque s/n. B1900FWA. La Plata, República Argentina. gustavbarrie@yahoo.com.ar

c Instituto Multidisciplinario de Historia y Ciencias Humanas (IMHICIHU), CONICET, Saavedra 15, piso 5, C1083ACA, Ciudad de Buenos Aires; FHumyAr-UNR. Rosario. República Argentina. $\bowtie$ lorenalheureux@gmail.com
\end{abstract}


1 (CC1) (Late Holocene, SW of Santa Cruz, República Argentina). The model predicts a decrease in the degree of bone preservation in an east-west direction and in relation to altitude, with a low potential in Spodosols and Inceptisols, intermediate in Andisols and higher in Entisols and Mollisols. The results of the macroscopic and microscopic study of the guanaco bones (Lama guanicoe) recovered in a probable mollisol at $\mathrm{CC} 1$, conform to the expectations of the model while suggesting that the main alteration factors are mineral leaching, bacterial activity and, above all, the action of roots.

KEY WORDS: Southern Patagonia, deciduous forest, soils, bone diagenesis, guanaco.

\section{INTRODUCCIÓN}

La Patagonia meridional ${ }^{1}$ constituye una de las regiones en la cual los estudios tafonómicos con orientación arqueológica poseen mayor desarrollo. Los estudios tafonómicos sobre fauna, tanto aquellos basados en observaciones actualísticas como en el análisis de evidencia arqueológica, han estado mayormente orientados a discernir las condiciones naturales y antrópicas que promueven y determinan el modo y el ritmo en que los huesos se acumulan $y$, eventualmente, se entierran o desentierran en sectores particulares del espacio (v.gr. Belardi \& Carballo Marina, 2003; Borella, 2004; Borrero, 2001, 2007; Borrero et al. 2006; Bottari \& Valiza Davis, 2019; Cruz, 2003, 2015; Marchionni, 2013; Marchionni et al. 2020; Martin, 1998; Martin \& Borrero, 2010; Muñoz, 2017; Muñoz \& Cruz, 2014). El estudio de las condiciones que promueven o impiden la preservación ósea en los depósitos sedimentarios ha tenido, por el contrario, menor desarrollo. En particular, el estudio analítico de las alteraciones físicas y químicas (i.e. diagenéticas; Hedges et al. 1995) experimentadas por los huesos en su contexto de enterramiento no ha sido abordado, aún, de manera extensiva y sistemática sino sólo de manera aislada (v.gr. Chadefaux, 2006, citado en Legoupil, 2009). Las probables razones de ello son múltiples. Una de las principales, tal vez, sea el hecho de que la degradación ósea acelerada, dada las condiciones ambientales generales de aridez o semiaridez al este de los Andes y las relativamente bajas temperaturas imperantes en el área (Oliva et al. 2001), constituye un problema de eventual impacto local (v.gr. Belardi et al. 2007) pero no regional, como sí lo es en otras zonas de Argentina (v.gr. centro-este de la provincia de Santa Fe; Galligani, 2020). En particular, la relativa abundancia de restos óseos en aleros y cuevas -históricamente, los focos preferenciales de la atención arqueológica en la región-, de alguna manera ha hecho menos acuciante la necesidad de investigar, en profundidad, los procesos diagenéticos experimentados por los huesos alli recuperados. Asimismo, la buena preservación de otros restos orgánicos (v.gr. carbón vegetal) en muchos de esos contextos, hizo que los huesos no hayan constituido, en general, la primera opción a la hora de seleccionar muestras para datarlas radiocarbónicamente (ver referencias citadas en Miotti \& Salemme, 2004; Pallo \& Ozán, 2014; Rubinos Pérez, 2003). De este modo, eventuales problemas en relación con la cantidad y calidad del colágeno óseo probablemente hayan pasado desapercibidos.

En las últimas tres décadas se ha producido una exploración arqueológica más intensa de ambientes a cielo abierto, tanto en la costa como en la estepa costera e interior (v.gr. Belardi et al. 2006; Borrazzo \& Borrero, 2011; Borrero, 1998; Borrero \& Charlin, 2010; Castro et al. 2003; Cruz \& Caracotche, 2006; Goñi, 2010; Magnin, 2010). Asimismo, se han popularizado los estudios isotópicos sobre huesos humanos y de animales para el abordaje de diferentes problemas (v.gr. Barberena, 2002; Tessone, 2010; Tessone et al. 2020a, 2020b; Zilio et al. 2018). Sin embargo, estos desarrollos no han traído aparejado un interés específico en el problema de la diagénesis ósea, más allá de la obtención de los datos básicos acerca de la cantidad y calidad del colágeno (DeNiro,

1 Si bien la mayoría de los estudios arqueológicos realizados en Argentina sigue la división regional de Patagonia propuesta por Gradín (1980, p. 179), según la cual Patagonia Meridional comprendería el espacio continental situado al sur del río Santa Cruz, en este trabajo optamos por una definición más amplia de la misma, que toma en cuenta los límites latitudinales (aunque no longitudinales) de la Subregión de los Bosques Meridionales (sensu Matteucci, 2018, pp. 530-531). De esta forma, el rótulo "Patagonia meridional" utilizado aquí incluye, aproximadamente, las divisiones Central y Meridional de Gradín (1980, p. 179). 
1985; van Klinken, 1999), que son de rutina en los estudios de isótopos estables del C y N y en las dataciones radiocarbónicas (a pesar del hecho de que, en este último caso, rara vez se informan). Esto es así a pesar de que evidencia preliminar indicaría que las probabilidades de supervivencia a muy largo plazo (varios miles de años) de los huesos enterrados en ambientes a cielo abierto es baja, particularmente de aquellos localizados a poca profundidad y en depósitos expuestos a la alternancia de períodos de humedad y sequedad muy marcados, a ciclos reiterados de congelamiento y descongelamiento y con un muy bajo aporte de minerales que permitan estabilizar la fase inorgánica del hueso (v.gr. chenques, base de paredones basálticos) (Barrientos et al. 2007; Belardi et al. 2007). Sin embargo, poco se sabe, en estos y otros casos, acerca de las modificaciones microestructurales de los huesos (v.gr. fisuramiento interno, aumento de la porosidad por bioerosión o hidrólisis del colágeno, pérdida de contenido mineral por disolución, etc.), implicadas en las tasas relativamente aceleradas de degradación ósea inferidas.

En el caso del bosque caducifolio de Nothofagus -cuya exploración arqueológica sistemática es, en general, más reciente que la de la costa o de la estepa interior-, casi todo lo que se conoce hasta el presente respecto de su uso u ocupación a través del tiempo deriva del estudio del registro lítico (v.gr. Belardi et al. 2020a; Carballo Marina et al. 2016; Pallo et al. 2020). En este sentido, la evaluación del potencial del registro zooarqueológico para contribuir a esta discusión es crítica (Borrero \& Muñoz, 1999). Si bien en Patagonia meridional el uso del bosque parece haber sido poco intenso y marginal respecto del de otros espacios (aunque con variaciones microrregionales; ver Aschero et al. 2005; Belardi \& Caracotche, 2005; Belardi \& Carballo Marina, 2014; Belardi et al. 2020a, 2020b; Borrero, 1994-1995; Borrero \& Muñoz, 1999; Carballo Marina et al. 2016; Espinosa et al. 2009; Franco, 2002; Pallo \& Borrero, 2015), es necesario determinar con precisión la existencia de sesgos introducidos ya sea por la poca visibilidad arqueológica o por la pérdida de evidencia por destrucción (Borrero \& Muñoz, 1999). Por ello, resulta crucial caracterizar el grado de alteración diagenética de los huesos depositados o enterrados en el bosque, como un primer paso para comprender los mecanismos implicados en su preservación o su degradación y, en este último caso, estimar la tasa de progresión.
Las observaciones o estudios de conjuntos óseos procedentes de ambientes de bosque caducifolio del sur de Patagonia continental sugieren que la preservación ósea es altamente variable. Ésta puede ser muy buena en el sur de Última Esperanza (Borrero \& Muñoz, 1999); relativamente buena en la zona del Chaltén (Belardi et al. 2020b), en el Parque Perito Moreno (Herrera, 1988; Tessone et al. 2020a) y en la cuenca del río Guillermo/Don Guillermo (Legoupil, 2009; L'Heureux \& Borrazzo, 2016); variable en el área lacustre al sur del lago Argentino (i.e. lagos Roca-Rico) (Borrero \& Muñoz, 1999; L'Heureux, 2003). Los conjuntos analizados hasta el presente provienen mayormente de sitios bajo abrigo, lo cual introduce sesgos en la percepción de tendencias en el grado de preservación de los restos óseos.

En este contexto, el objetivo de este trabajo es doble. Por un lado, formular un modelo inicial que dé cuenta de los procesos probablemente implicados en la destrucción o preservación, a largo plazo, de los huesos enterrados en ambientes de bosque patagónico a cielo abierto en Patagonia meridional y, por el otro, aportar a la caracterización analítica de la diagénesis ósea a escala local, considerando variables definidas a diferentes niveles estructurales. Para ello se realizará, en primer lugar, una breve introducción al problema de la diagénesis ósea, describiendo sintéticamente los factores que influyen sobre ella y el modo en que tales factores se presentan y distribuyen en el bosque patagónico, particularmente en la vertiente Atlántica de los Andes. El propósito de este ejercicio es derivar una serie de expectativas acerca de las variaciones espaciales en la preservación ósea dentro del bosque. En segundo lugar, se presentarán y discutirán los resultados de los estudios llevados a cabo sobre el conjunto óseo de guanaco (Lama guanicoe) recuperado en el sitio Cancha Carrera 1 (sudoeste de la provincia de Santa Cruz, República Argentina). Se espera, de este modo, sentar las bases para futuras investigaciones sobre los patrones de alteración diagenética de restos óseos en este tipo de ambientes. Ello contribuirá a una mejor evaluación del potencial del registro zooarqueológico para permitir la discusión del uso prehispánico del bosque a nivel regional y sus aparentes variaciones intra e interregionales (para una visión actualizada sobre el tema, ver De Angelis \& Belardi, 2020). 
DIAGÉNESIS ÓSEA: EXPECTATIVAS PARA EL BOSQUE CADUCIFOLIO PATAGÓNICO (COMPLEJOS BOSQUES HÚMEDOS MERIDIONALES Y BOSQUES MERIDIONALES DE TRANSICIÓN)

\section{Breve introducción al problema de la diagénesis ósea}

Se denominan alteraciones o modificaciones diagenéticas en sentido estricto (para una definición del término en sentido amplio, ver Müller, 1963) al conjunto de los cambios, tanto físicos como químicos (v.gr. disolución parcial o completa, bioerosión, precipitación, recristalización, captación de iones por sorción y difusión, hidrólisis, repolimerización), que experimentan los huesos en su contexto de depositación y enterramiento (Hedges et al. 1995; Kendall et al. 2018; Trueman, 1999; Trueman \& Tuross, 2002). El tipo y grado de expresión de estas alteraciones depende de factores intrínsecos (propios del hueso), factores extrínsecos (característicos del entorno de depositación) y, en menor medida, de factores dependientes de eventos o procesos ocurridos con anterioridad al enterramiento (Henderson, 1987; Kendall et al. 2018; Linse, 1992; Von Endt \& Ortner, 1984; Wheeler \& Jones, 1989).

Los factores intrínsecos básicos son porosidad, densidad, forma, tamaño y propiedades químicas del hueso. Éstos son dependientes de un conjunto de factores individuales, tales como el sexo, la edad y el estado metabólico del individuo. Los factores extrínsecos más influyentes son el tipo de suelo, el $\mathrm{pH}$ del sedimento, el drenaje y el régimen hidrológico local, la temperatura, la disponibilidad de oxígeno, la flora y fauna macroscópica y microscópica (para una sintesis reciente, ver Kendall et al. 2018). Durante los últimos 25 años, el conocimiento acerca de la interacción entre estos diferentes factores se ha incrementado notablemente, lo cual se refleja en modelos de diagénesis ósea a diferentes niveles, particularmente el microestructural y el molecular (v.gr. Berna et al. 2004; Bocherens et al. 1997; Collins et al. 1995, 2002; Hedges, 2002; Hedges et al. 1995, 2007; Kendall et al. 2018; NielsenMarsh \& Hedges, 2000; Pike et al. 2001; Smith et al. 2007). La principal razón para ello es que son los cambios en los niveles más bajos, dentro de la jerarquía estructural del hueso, los responsables de la capacidad de respuesta de éste a los diferentes factores del suelo (Kendall et al. 2018).

Estudios llevados a cabo en la zona templada de Europa, basados en el análisis conjunto de múltiples parámetros, indican que la cantidad de vías diagenéticas es notoriamente reducida, no específica de ningún sitio en particular, pudiéndose identificar con claridad sólo cuatro de ellas: a) buena preservación, b) hidrólisis acelerada del colágeno, c) disolución catastrófica y d) ataque microbiano (Hedges et al. 1995, p. 208; Smith et al. 2007, p. 1489). Con excepción de la hidrólisis acelerada del colágeno, que obedece a circunstancias muy particulares (i.e. eventos de alta temperatura, suelos alcalinos y ciclos extremos de humedecimiento y secado de los huesos; Smith et al. 2002), la disolución catastrófica y el ataque microbiano son fenómenos relativamente frecuentes que, eventualmente, pueden vincularse entre sí (Smith et al. 2007). El principal aspecto en común entre estas dos formas de diagénesis es el aumento de la mesoporosidad del hueso (diámetro $>0,1 \mu \mathrm{m}<8,5 \mu \mathrm{m}$; Turner-Walker et al. 2002). En el caso de los huesos atacados por microorganismos (particularmente bacterias; TurnerWalker, 2012, 2019), este aumento de la porosidad intermedia permite una mayor interacción con el agua del suelo (principalmente bajo regímenes hidrológicos de recarga y flujo; sensu Hedges \& Millard, 1995) y, por lo tanto, una aceleración de la disolución mineral. A su vez, la disolución aumenta la porosidad del hueso y, cuanto mayor es ésta, mayor es la velocidad de disolución, lo que conduce a una pérdida catastrófica de mineral (Pike et al. 2001). La química del suelo, por su parte, afectaría de manera significativa sólo a la pérdida mineral o disolución mineral catastrófica (Nielsen-Marsh et al. 2007), mientras que su textura y permeabilidad afectarían a los niveles de actividad de la microflora bacteriana aeróbica, que es mayor en suelos bien drenados y aireados y menor, o inexistente, bajo condiciones de anegamiento permanente o semipermanente (con una alta probabilidad, las bacterias capaces de producir bioerosión en el hueso bajo condiciones naturales son sólo aeróbicas; Kendall et al. 2018; Turner-Walker, 2012, 2019).

En suelos definidos como "corrosivos" (i.e. con bajos niveles de $\mathrm{pH}$ y materia orgánica, buen drenaje y ausencia de roca calcárea capaz de aportar cationes de $\mathrm{Ca}$ ), la preservación resultaría poco 


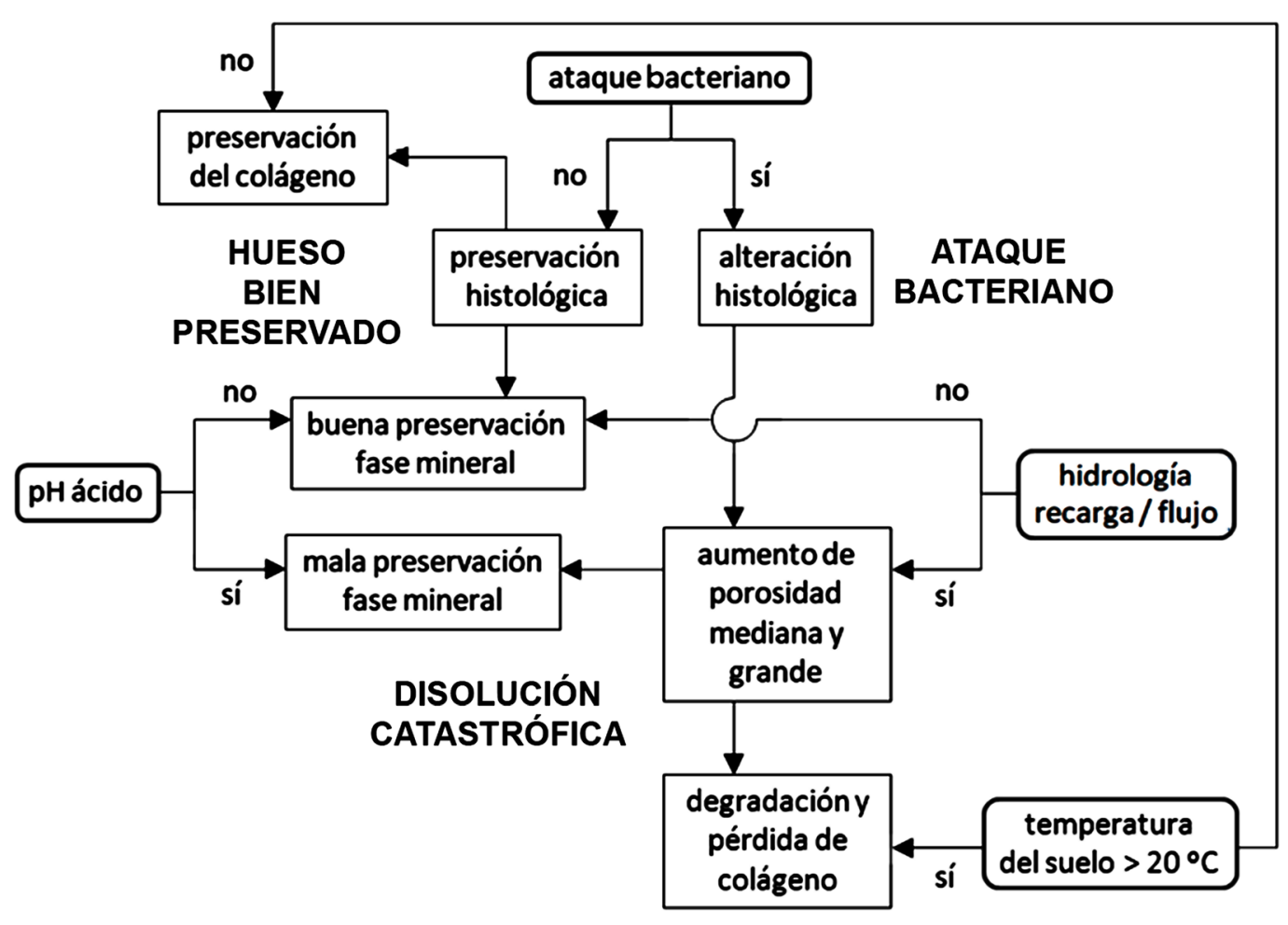

Fig. 1. Modelo de vías diagenéticas del hueso (Smith et al. 2007), excluyendo la hidrólisis acelerada del colágeno. Modificado a partir de Galligani (2020).

probable a largo plazo. En suelos "benignos" (i.e. con pH neutro a básico, con alto contenido de materia orgánica y cationes de Ca intercambiable), por el contrario, se esperaría una buena preservación de los huesos (Nielsen-Marsh et al. 2007). El conjunto de estas relaciones puede visualizarse en la Fig. 1. Cabe señalar que, a lo largo de cada una de las vías diagenéticas mencionadas, las modificaciones en el hueso tienden a ocurrir gradualmente, aunque a velocidades diferentes en función, principalmente, de los valores de los factores extrínsecos y de la etapa de la historia tafonómica de un elemento o de un conjunto óseo (Kendall et al. 2018; Smith et al. 2007).

Probables determinantes de la diagénesis ósea en el bosque caducifolio de los Complejos Bosques Húmedos Meridionales y Bosques Meridionales de Transición

La ecorregión Bosques Patagónicos (Matteucci, 2018), que recibe también el nombre de Bosques Subantárticos, Bosques Andinos-Patagónicos o
Provincia Fitogeográfica Subantártica (Cabrera, 1976; Dimitri, 1972; Oyarzabal et al. 2018) se extiende, en Argentina, como una estrecha franja sobre el macizo cordillerano desde el norte del Neuquén hasta Tierra del Fuego e isla de los Estados (ca. 37$55^{\circ}$ Lat. Sur). Entre el sur de Chubut y la isla de los Estados se encuentra la Subregión de los Bosques Meridionales y, dentro de ella, los Complejos Bosques Húmedos Meridionales y Bosques Meridionales de Transición (Matteucci, 2018). En el primero de estos complejos se hallan bosques puros de notofagáceas, tanto perennes como deciduas: guindo o coihue (Nothofagus betuloides; perenne), lenga (N. pumilio; decidua) y ñire (N. antarctica; decidua); asimismo, se encuentran bosques mixtos de lenga y guindo, de lenga y canelo (Drimys winteri, una winterácea perenne) y de lenga y ñire (Matteucci, 2018; Moore, 1983; Peri \& Ormaechea, 2013), aunque en proporciones muy dispares. En el segundo, que forma una franja muy angosta y discontinua, localizada al este del Complejo Bosques Húmedos Meridionales, la vegetación es ecotonal, con bosques de lenga en los valles protegidos y bosques y matorrales de ñire 
puros o mixtos con lenga en sitios más expuestos (Matteucci, 2018). En el último inventario efectuado en la provincia de Santa Cruz (año 2013), del total de la superficie cubierta por bosques (535.889 ha), el $68,9 \%$ corresponde a lenga, el $29,8 \%$ a ñire y sólo el $1,3 \%$ restante a bosque mixto (Peri \& Ormaechea, 2013).

En Patagonia meridional al este de los Andes, la distribución de los bosques de lenga y ñire se asocia con dos gradientes: uno en sentido oesteeste, determinado por la disponibilidad de agua, y uno altitudinal, determinado por la temperatura (Matteucci, 2018; Moore, 1983; Pereyra, 2012). En este marco, los bosques pasan de húmedos a mésicos, limitando luego con la estepa xérica oriental. Si bien la lenga y el ñire, en comparación con otras especies de Nothofagus, son muy similares en cuanto al rango, el tipo de ambiente y la variación altitudinal (Prémoli \& Mathiasen, 2013), puede decirse que, en términos generales y de manera muy simplificada, la lenga tiende a ocupar la parte más húmeda de la franja boscosa, así como las zonas más altas y frías (típicamente constituye el límite superior del bosque; Cabrera, 1976; Dimitri, 1972). El ñire, por su parte, tiende a ocupar la porción menos húmeda y las zonas más bajas o menos frías (Peri \& Monelos, 2006; Villegas, 2004; Villegas et al. 2007), aunque su gran plasticidad fenotípica le permite resistir heladas de $-22^{\circ} \mathrm{C}$ (Alberdi, 1995) y, en ocasiones, compartir con la lenga el límite superior del bosque, en ambos casos con un morfotipo achaparrado (Matteucci, 2018; Mondino et al. 2019; Pérez Moreau, 1959; Pisano, 1977; Prémoli \& Mathiasen, 2013). Mientras que la lenga crece en zonas de pendientes moderadas y fuertes (Mondino et al. 2019), la gran mayoría de los bosques de ñire (ñirantales) se desarrolla en sitios de baja pendiente $\left(0^{\circ}\right.$ a $5^{\circ}$; Peri \& Ormaechea, 2013). Ejemplos de ello son los bosques de la parte baja de la cuenca del río Guillermo (Pallo \& Borrero, 2015) y del curso inferior del río Penitente (Belardi et al. 2020a).

A lo largo del Holoceno, los límites orientales del bosque han sido dinámicos, con avances y retrocesos del ecotono bosque-estepa a través del tiempo (Mancini et al. 2011; Moreno et al. 2019; para una sintesis de la evolución del bosque patagónico meridional desde una perspectiva arqueológica, ver Pallo \& Borrero, 2015, pp. 214-215).

A continuación, se describirán las principales condiciones climáticas, edáficas, hidrológicas y microbiológicas del bosque caducifolio de lenga y ñire, de interés para la generación de expectativas mínimas acerca de los procesos diagenéticos que podrían afectar a los huesos allí enterrados.

\section{CLIMA}

En los bosques meridionales, el clima es templado, lluvioso, sin estación seca definida, pero con menor precipitación en verano. La temperatura media anual es de $7,5^{\circ} \mathrm{C}$, la media mensual de julio es de $0,6^{\circ} \mathrm{C}$ y la de enero de $13,4^{\circ} \mathrm{C}$ (datos para el Parque Nacional Los Glaciares; Matteucci, 2018). En esta región, la mayor parte de las precipitaciones es producto de la descarga de nubes estratiformes, que se desarrollan a lo largo de frentes cálido-fríos (Garreaud et al. 2009). Además de la precipitación por frentes, la elevación de vientos (vientos constantes del $\mathrm{O} / \mathrm{SO}$ ) por sobre la ladera oeste de los Andes, produce precipitaciones de tipo orográficas por enfriamiento adiabático, alcanzando un máximo local de $8.000 \mathrm{~mm}$ anuales en la zona del Campo de Hielo Patagónico Sur (Carrasco et al. 2003; Escobar et al. 1992). En contraste, hacia el este de la cordillera de los Andes las precipitaciones varían dramáticamente, en sentido O-E, entre 1.300 y 200$250 \mathrm{~mm}$ anuales, dentro de una franja de alrededor de 50 km a partir del cordón montañoso (Carrasco et al. 1998; Rosenblüth et al. 1997; Skvarca, 2002). En invierno, la precipitación se transforma en nieve por sobre los $600 \mathrm{msnm}$, tornando intransitables los valles intermontanos debido a la gran cantidad de acumulación nivosa en el oeste de la Cordillera (Villalba et al. 2003).

\section{SUELOS}

Los bosques de lenga y ñire crecen sobre suelos de rápida evolución pedogenética, correspondientes a los órdenes (según la taxonomía de la USDA; Soil Survey Staff, 1975) Espodosoles, Inceptisoles, Andisoles y Entisoles (v.gr. área intermedia entre los lagos San Martín y Viedma; Villegas, 2004), Molisoles (v.gr. Cancha Carrera, Zona de Río Turbio; Cruzate et al. 2007; Gargaglione et al. 2017; Pereyra, 2012) y Aridisoles (v.gr. cuenca superior del río Santa Cruz; Cruzate et al. 2007; Peri \& Ormaechea, 2013). Son suelos que evolucionan sobre geoformas muy jóvenes, aún sujetas a morfogénesis y a recurrentes eventos de depositación de cenizas; se asocian a superficies 
suavemente onduladas, correspondientes a morenas y/o rocas aborregadas, a relieves planos de planicies glacifluviales y glacilacustres (Villegas, 2004; Villegas et al. 2007). Los materiales parentales más frecuentes son tefras, till, gravas, arenas fluviales y coluvio (Pereyra, 2012; Villegas et al. 2007). Por ello, la característica más notoria de estos suelos es su textura gruesa, donde la clase más frecuente es la francoarenosa, con abundancia de fragmentos de tamaño grava media y, en muchos casos, pedregosidad, tanto en superficie como en profundidad (Villegas, 2004). Son suelos poco profundos $(<1 \mathrm{~m})$, con discontinuidades litológicas y baja retención hídrica (Villegas et al. 2007).

La capacidad de intercambio catiónico (CIC) presenta un amplio espectro de valores, siendo mayor en los Molisoles, Entisoles y Andisoles y menor en los Inceptisoles y Espodosoles. En cuanto al grado de saturación con "bases", los Molisoles presentan valores entre 50 y $80 \%$, los Entisoles y Andisoles entre el 40 y 60\%, mientras que los Espodosoles varían entre el 26 y el $46 \%$ (Villegas, 2004). En general, hay un gradiente E-O en la disminución de la saturación con bases (desaturación): los mayores valores se encuentran en los Entisoles (Torriortentes y Torripsamentes) y los menores entre los Espodosoles. Acorde con esto, el pH (en agua) de los suelos disminuye (acidificación): 7,5-8,5 en Entisoles (Torriortentes y Torripsamentes); 6,2-7 en Molisoles; 5,2-5,9 en Inceptisoles y Andisoles; 4-4,3 en Espodosoles. Todos estos suelos poseen un régimen de humedad údico, con transición al xérico hacia el E (Pereyra, 2012; Villegas, 2004). El régimen de temperatura es mésico para Molisoles, mésico y críico para Entisoles, Inceptisoles y Andisoles y críico (en altura) para Espodosoles (Pereyra, 2012; Villegas, 2004).

\section{REGÍMENES HIDROLÓGICOS}

La combinación de los regímenes údico y críico de los suelos de los bosques meridionales (Pereyra, 2012; Villegas, 2004), implica una alta tasa de precipitaciones (bajo la forma de agua líquida y de nieve) y una muy baja evapotranspiración (Villegas et al. 2007). Esto resulta en un predominio de los procesos de recarga (i.e. infiltración de aguas meteóricas desde la superficie del terreno hasta el sistema de agua subterránea, con flujo a través de la zona no saturada) frente a la evapotranspiración, a lo largo de prolongados periodos del año (Anderson et al. 2015). Estas condiciones, junto con la permeabilidad y pobreza en arcillas de los materiales parentales promueven, en áreas con buen drenaje, una fuerte lixiviación y una moderada podsolización de los suelos, particularmente en Inceptisoles y Espodosoles (Pereyra, 2012; Villegas et al. 2007).

\section{MICROBIOTA}

En el bosque patagónico, los estudios acerca de las características microbiológicas de los suelos son escasos (Dube et al. 2009; Gargaglione et al. 2017, 2018; González Polo et al. 2013). Los trabajos de Gargaglione y colaboradores, realizados en ñirantales del área de Cancha Carrera, en el SO de Santa Cruz, muestran que existen diferencias en biomasa microbiana entre los suelos del bosque y el pastizal aledaño, siendo el bosque primario el que presenta mayores valores (Gargaglione et al. 2018). Asimismo, se ha detectado una diferencia en los valores de biomasa microbiana entre ñirantales del complejo Bosques Húmedos Meridionales y un bosque mixto de $N$. dombeyi, $N$. nervosa y N. obliqua del complejo Bosques Húmedos Septentrionales (sensu Matteucci, 2018), siendo menores en el primero (1090-1328 $\mu \mathrm{g} \mathrm{C/g} \mathrm{y} \mathrm{1000-2000} \mathrm{\mu g} \mathrm{C/g,}$ respectivamente) (Gargaglione et al. 2017; González Polo et al. 2013). Gargaglione y colaboradores (2017) sugieren que las diferencias observadas, aunque preliminares, pueden estar vinculadas al hecho de que, en el norte de Patagonia, la temperatura y las condiciones ambientales tienden a ser menos rigurosas que en el extremo sur de la región. Esto sería concordante con el hecho demostrado de que la temperatura es uno de los factores ambientales más importantes en la regulación de la actividad y la determinación de la composición de la microbiota, en particular de la comunidad bacteriana (Nottingham et al. 2018; Pettersson \& Bååth, 2003).

\section{EXPECTATIVAS DIAGENÉTICAS}

Debido a su alta permeabilidad, pH ácido, bajo contenido de materia orgánica y de bases intercambiables, los cinco órdenes de suelos en los cuales se desarrolla el bosque entran dentro de la categoría de corrosivos en relación con su 
RÉGIMEN DE HUMEDAD

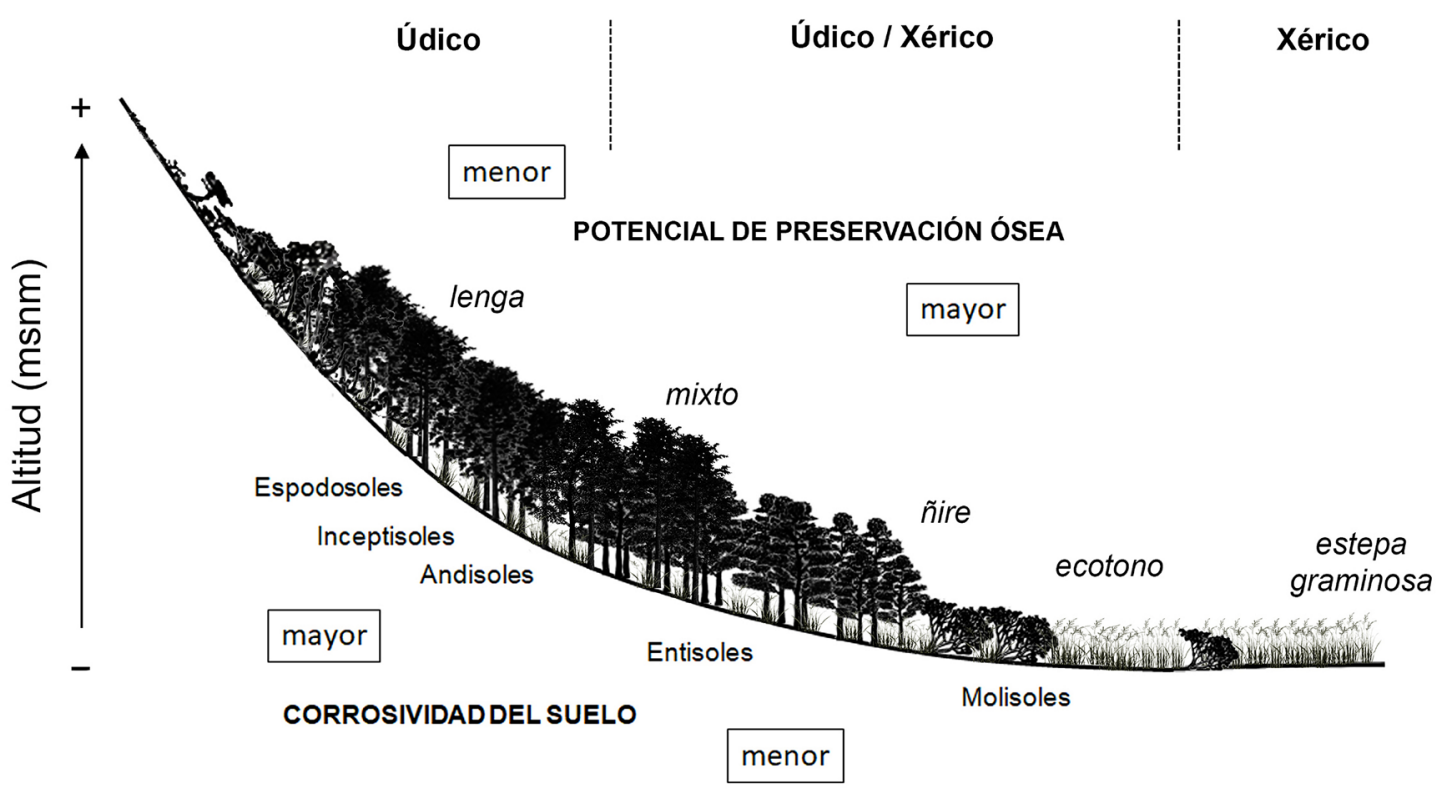

Oeste

Este

Fig. 2. Potencial de preservación ósea en función del nivel inferido de corrosividad (sensu Nielsen-Marsh et al. 2007) de los suelos en los bosques de lenga y ñire de Patagonia meridional. Modelo esquemático y simplificado de distribución de especies arbóreas y suelos, elaborado a partir de Gargaglione y colaboradores (2017), Pereyra (2012), Peri y Monelos (2006),

Villegas (2004) y Villegas y colaboradores (2007).

potencial de alteración diagenética de los huesos (sensu Nielsen-Marsh et al. 2007). Sin embargo, pueden establecerse algunas distinciones entre ellos. Los que presentan la peor combinación de factores negativos para la preservación a largo plazo de los huesos son los Espodosoles y los Inceptisoles. Los Andisoles ocuparian una posición intermedia, mientras que los Entisoles y los Molisoles (con un rango de $\mathrm{pH}$ combinado de 6,2-8,5, i.e. ligeramente ácido a alcalino) serían aquellos con mejor potencial de preservación.

Además de los factores vinculados con las propiedades físicas y químicas de los suelos y con la microbiota asociada, un factor de significativa importancia en los bosques en general y en los bosques patagónicos en particular, son las raíces, tanto de los árboles como de las herbáceas, gramíneas, graminoides, arbustos y subarbustos que componen el sotobosque (Peri \& Ormaechea, 2013). Las raíces ejercen, sobre los elementos óseos, una acción física (invasión de los vacíos estructurales, ruptura del hueso por presión de turgencia; Gabet et al. 2003; Pokines \& Baker, 2014) y química (secreción de una variedad de compuestos orgánicos, incluidos ácidos, que pueden ayudar a solubilizar el mineral del hueso; Koo et al. 2005; Pokines \& Baker, 2014). Diferentes autores (v.gr. Arrigoni, 1991; Arrigoni \& Fernández, 2004; Borrero \& Muñoz, 1999; L'Heureux \& Borrazzo, 2016) han señalado el impacto de este factor sobre la superficie y la macroestructura ósea en ambientes de bosque patagónico. Sin embargo, hasta el presente no existen trabajos que hayan evaluado, en la región, el tipo y magnitud del daño causado por las raíces a nivel microestructural.

Sobre la base de lo expuesto, puede decirse que se esperan niveles de medios a bajos y muy bajos de preservación, siguiendo aproximadamente un gradiente en sentido E-O (Fig. 2). El principal tipo de alteración diagenética podría ser la disolución progresiva de la fase mineral, por lixiviación y ataque químico, y el consecuente aumento de la porosidad (meso y macroporosidad). Este proceso 
podría, eventualmente, ser potenciado por la actividad bacteriana, causante de bioerosión, la cual también contribuye al aumento de la mesoporosidad y de la reactividad del hueso al agua del suelo (Kendall et al. 2018). Sin embargo, dada la baja temperatura ambiente y de los suelos, se espera un impacto relativamente bajo de este factor biológico sobre la diagénesis ósea (Turner-Walker, 2019), particularmente en relación con lo observado en ambientes más cálidos del Cono Sur de Sudamérica (v.gr. Galligani et al. 2019; Morales et al. 2018). Por la misma razón climática, no se espera que la pérdida del colágeno óseo por hidrólisis tanto enzimática como química (Child, 1995) constituya un factor de alteración diagenética de importancia en los bosques meridionales.

Asimismo, se espera que en los sitios a cielo abierto -situados tanto en el bosque como en la estepa-, cuyas capas superficiales del suelo estén sometidas a ciclos alternantes de congelamientodescongelamiento (Oliva et al. 2001), una alteración significativa consista en la existencia de fisuras internas concéntricas (Guadelli, 2015; Miller, 1975; Pokines et al. 2016). A este respecto, se ha observado que el agua congelada dentro de los poros y fisuras del hueso posee un gran potencial para contribuir, aún más, al agrietamiento causado por la meteorización subaérea (Guadelli, 2008, 2015; Matsuoka, 1996; Pokines et al. 2016). Esto explicaría, al menos en parte, el patrón de fisuramiento interno registrado por Morales y colaboradores (2017) en huesos de guanaco depositados en superficie en ambientes esteparios de la cuenca de los lagos San Martín y Tar, en el centro-oeste de la provincia de Santa Cruz.

Las expectativas diagenéticas arriba indicadas, si bien pueden ser válidas para diferentes especies de vertebrados, son particularmente apropiadas para ungulados (v.gr. camélidos, cérvidos), ya que muchas de las observaciones que las sustentan provienen de estudios centrados en este superorden de mamíferos. Asimismo, son aplicables a sitios a cielo abierto o bajo abrigo rocoso en los que el suelo bajo el área cubierta se encuentra influenciado por factores semejantes a los del área circundante (v.gr. sitios bajo bloques erráticos o de derrumbe), no siendo extensivo a aleros profundos o cuevas.

Por último, cabe consignar que, a pesar de las variaciones ocurridas en la extensión y densidad del bosque a lo largo del Holoceno, no se espera que el factor de evolución paleoambiental influya significativamente sobre las predicciones del modelo actualístico propuesto. Esto se debe a que las características y propiedades de los suelos actuales son, de hecho, el resultado de diversos procesos de formación y la interacción de distintos factores, entre los que se encuentran el material parental, el clima, el relieve, los macro y microorganismos y el tiempo (Buol et al. 2011, pp. 89-140). Si bien los valores de algunas variables pueden modificarse dentro de ciertos límites (v.gr. pH) y los suelos mismos pueden cambiar por formación de nuevos horizontes, por enterramiento, o por erosión o truncamiento, no se producen transformaciones drásticas que impliquen el cambio de un suelo de un orden a otro, al menos en la escala de tiempo acotada que estamos considerando aquí.

\section{EL SITIO CANCHA CARRERA 1 (CC1)}

\section{Contexto ambiental}

El área de Cancha Carrera se encuentra localizada en el sudoeste de la provincia de Santa Cruz, en la cuenca del río Guillermo (río Don Guillermo en territorio chileno), inmediatamente al SE y NE de la Sierra del Cazador y de la Sierra Rogers, respectivamente (Fig. 3). Toma su nombre de la Estancia Cancha Carrera y del paso fronterizo que comunica este espacio con Villa Cerro Castillo y el Parque Nacional Torres del Paine, en Chile. Es un ambiente subandino, con precipitaciones que rondan los 300 y $350 \mathrm{~mm}$ anuales y una temperatura media anual entre $6^{\circ} \mathrm{C}$ y $7^{\circ} \mathrm{C}$ (Oliva et al. 2001; Oyarzabal et al. 2018).

La mayor parte de la cuenca del río Guillermo actualmente se encuentra cubierta por una estepa de coirón (Festuca gracillima) (Oliva et al. 2001) y de espiguilla o poa común (Poa pratensis) bajo pastoreo (Peri \& Ormaechea, 2013), con manchones degradados y no continuos de bosque de Nothofagus. Entre los 250 y $650 \mathrm{msnm}$, el bosque de lenga ocupa las laderas y las zonas más altas, mientras que formaciones de ñires se ubican en la transición estepa-lenga (Peri \& Ormaechea, 2013). Bosques de nire de cobertura intermedia rodean la cuenca media del río, mientras que pequeños parches muy abiertos o degradados se ubican al norte y otros relictos de bosque se localizan a unos cuantos kilómetros al este 

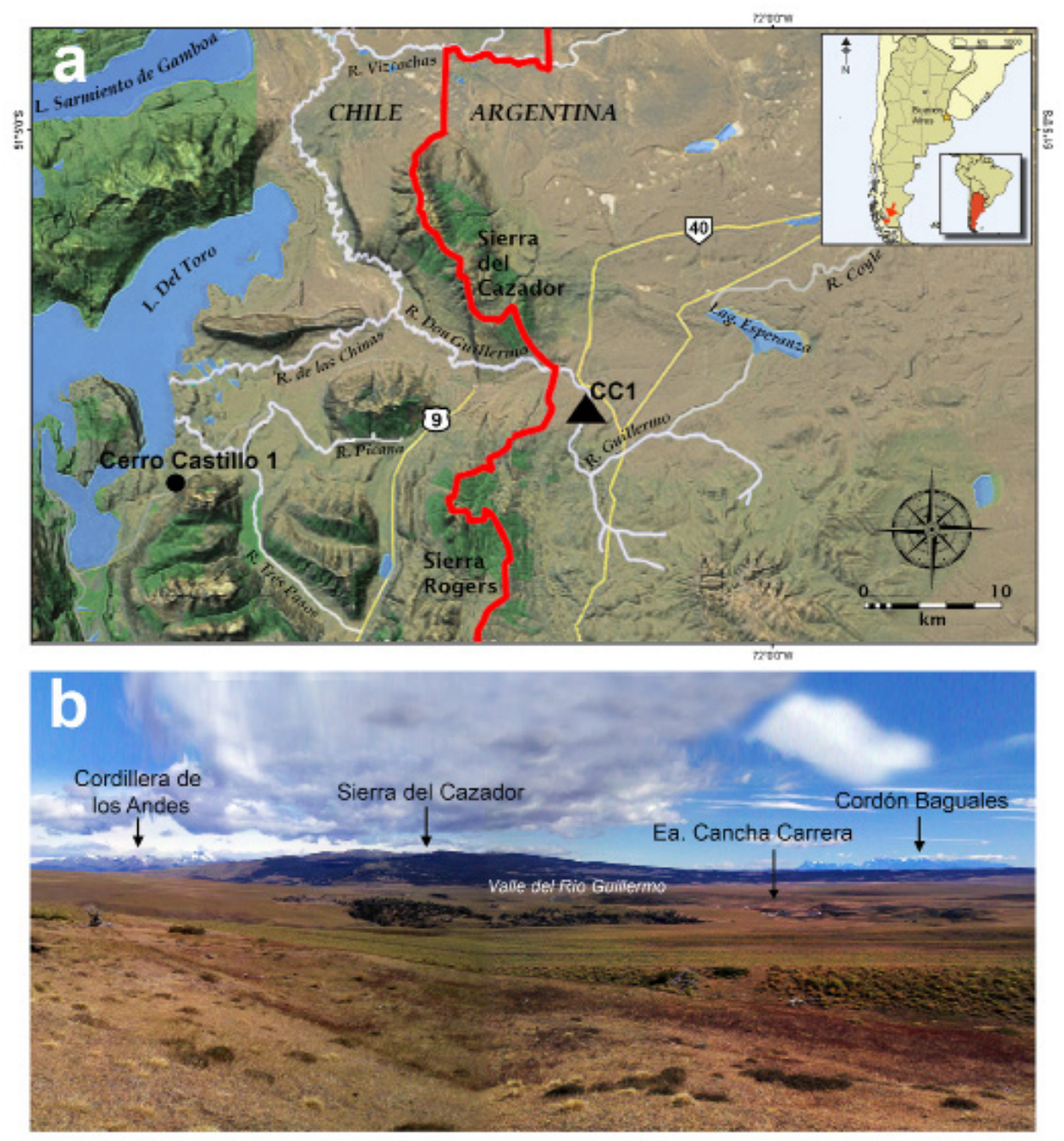

Fig. 3. Cancha Carrera. a) Localización de los sitios mencionados en el texto: Cancha Carrera 1 (CC1) y Cerro Castillo 1.

La base del mapa resulta de la combinación de la imagen de relieve de Google Maps

(https://www.google.com/maps/@-51.2666729,-72.189154,9.5z/data=!5m1!1e4) y la imagen Google Earth Pro de la misma zona, correspondiente a diciembre de 2016. b) Panorámica del valle del río Guillermo visto desde CC1; se observan los parches de bosque de ñire (zonas bajas) y lenga (zonas altas de la Sierra del Cazador).

del valle (Peri \& Ormaechea, 2013; Peri et al. 2013). La interacción de procesos antrópicos y naturales, tales como la desertificación, praderización, la acción de los fuegos y la actividad ganadera intensiva, habría reducido notablemente la cobertura boscosa de la zona (Huber et al. 2004; Mancini et al. 2011; Peri \& Ormaechea, 2013; Pisano, 1989-1990), que actualmente se registra en el área como manchones discontinuos de bosque (Fig. 4a).

En esta área, los bosques se desarrollarían sobre Molisoles (Cruzate et al. 2007), aunque tal clasificación es válida en una escala amplia
(1:1.000.000). Por ello, no se descarta que puedan existir variaciones locales no descritas. En el caso puntual de CC1 -un sitio de bosque en proceso de destrucción, localizado en un parche degradado de Nothofagus antarctica-, no se ha realizado aún un estudio edafológico in situ orientado a determinar el tipo de suelo en el cual se encuentran los materiales detectados y recuperados. Sin embargo, como parte del presente estudio se analizaron seis muestras de sedimento extraídas a diferentes profundidades de los perfiles de los dos sondeos estratigráficos excavados en el sitio (ver más abajo). Los análisis, 

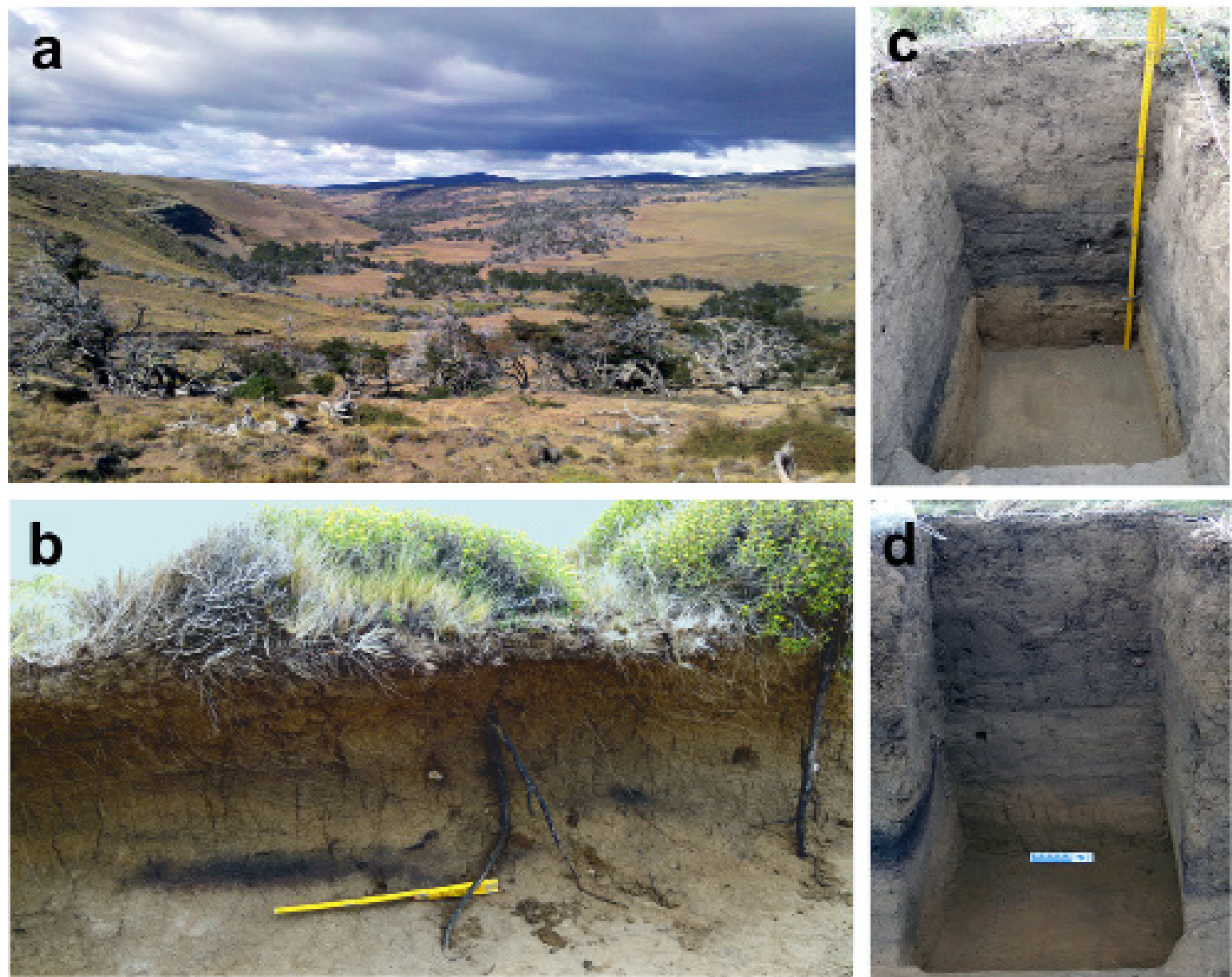

Fig. 4. Imágenes del sitio CC1. a) Vista desde el sitio hacia el SO (valle del río Guillermo), en donde se observan parches de bosque de ñire en las laderas y a lo largo del río. b) Segmento del perfil, donde se aprecian lentes de carbón y parte del material óseo expuesto (año 2014). c) Pozo de Sondeo 1. d) Pozo de Sondeo 2. Imágenes c y d cortesía de K. Borrazzo.

Tabla 1. Datos de la textura y química del suelo de Cancha Carrera 1 (CC1).

\begin{tabular}{lcccccl}
\hline Muestras & $\begin{array}{c}\mathrm{pH} \text { agua } \\
(1: 2,5)\end{array}$ & Arcilla (\%) & $\begin{array}{c}\text { Limo } \\
(\%)\end{array}$ & $\begin{array}{c}\text { Arena fina } \\
(\%)\end{array}$ & $\begin{array}{c}\text { Arena gruesa } \\
(\%)\end{array}$ & Clase Textural \\
\hline Sondeo $120-25 \mathrm{~cm}$ & 6,6 & 6,0 & 20,7 & 31,2 & 42,0 & Franco \\
Sondeo 1 40-45 cm & 6,5 & 10,0 & 24,0 & 29,5 & 36,5 & Franco Arenoso \\
Sondeo $170-75 \mathrm{~cm}$ & 6,9 & 20,0 & 18,9 & 39,4 & 21,8 & Franco Arenoso \\
Sondeo 2 35-40 cm & 6,0 & 10,0 & 23,0 & 54,6 & 12,4 & Franco Arenoso \\
Sondeo 2 65-70 cm & 6,2 & 12,0 & 21,5 & 43,0 & 23,5 & Franco Arenoso \\
Sondeo 2 90-95 cm & 5,5 & 12,0 & 25,2 & 41,2 & 21,6 & Franco Arenoso \\
\hline
\end{tabular}


llevados a cabo por el Laboratorio de Análisis de Suelos de la Facultad de Ciencias Agrarias de la Universidad Nacional de Rosario, consistieron en determinaciones de $\mathrm{pH}$ en agua (relación 1:2,5) y de textura. Los resultados obtenidos (Tabla 1 ) indican que el suelo es de textura predominantemente franco-arenosa, con valores de $\mathrm{pH}$ situados dentro del rango 5,5-6,9 (medianamente ácido a neutro). Las mencionadas características no son incompatibles con las predominantes en los molisoles del área.

\section{Resumen de la información arqueológica}

Este sector comenzó a trabajarse con un interés arqueológico debido a su localización geográfica y a su carácter de espacio intermedio entre la región de Última Esperanza, en Chile, y la estepa oriental, en Argentina. Los trabajos en el área de Cancha Carrera generaron una evidencia arqueológica relativamente escasa (Borrero, 2012-2015; Carballo Marina et al. 2016; L'Heureux \& Borrazzo, 2016; Pallo \& Borrazzo, 2017; Pallo \& Borrero, 2015; Pallo \& Cirigliano, 2018), en marcado contraste con el lado chileno de la cuenca. Por ejemplo, para un sector contiguo a la cuenca del río Don Guillermo, se destaca la elevada densidad de hallazgos registrada en el cercano sitio Cerro Castillo 1, ubicado al SO de Cancha Carrera 1 (Emperaire \& Laming, s/f, en Legoupil, 2009; Langlais \& Morello, 2009; San Román \& Morello, 2003) (Fig. 3). La evidencia lítica y ósea en este sitio sugiere un uso vinculado a la caza y al procesamiento de guanacos.

En el área de Cancha Carrera, el sitio más investigado es Cancha Carrera 1 (CC1). Éste se localiza sobre una lomada con parches degradados de ñire (Fig. 4a), a 320 msnm (51 ${ }^{\circ} 16^{\prime}$ S; 72²'W) (Figs. 3 y 4). Consiste en una cicatriz erosionada (corte de pendiente), con orientación S-SO con una muy buena visibilidad arqueológica. El perfil tiene alrededor de $25 \mathrm{~m}$ de largo y hasta $1 \mathrm{~m}$ de altura (Fig. 4b), presenta materiales óseos y líticos expuestos y lentes de carbón (L'Heuruex \& Borrazzo, 2016). En este sitio se realizaron recolecciones superficiales controladas y se excavaron dos pozos de sondeo (Sondeo 1 y Sondeo 2) (Figs. 4c y 4d). Éstos, de 0,5 x $0,5 \mathrm{~m}$, se plantearon a partir del borde del perfil. Las extracciones fueron de $5 \mathrm{~cm}$ de potencia (con excepción de la primera extracción de cada sondeo, de $10 \mathrm{~cm}$ ), registrándose los niveles naturales.
Las excavaciones se interrumpieron luego de dos extracciones sin hallazgos; las profundidades máximas alcanzadas fueron de 80 y $90 \mathrm{~cm}$, respectivamente (L'Heureux \& Borrazzo, 2016).

Para el sitio se cuentan con cuatro dataciones radiocarbónicas realizadas sobre elementos óseos de guanaco con modificaciones de origen antrópico, que ubican la ocupación del sitio en el Holoceno tardío final. Dos de las fechas se obtuvieron a partir de muestras óseas procedentes de la recolección superficial del año 2012 (Pallo \& Borrero, 2015), cuyas edades radiocarbónicas convencionales y calibradas son $848 \pm 45$ (AA-98673) (1.157-1.285 cal AD) y 998 \pm 45 (AA-98671) (994-1.183 cal AD). Las dos fechas restantes provienen de especímenes de L. guanicoe recuperados en cada uno de los sondeos realizados en el año 2014 (L'Heureux \& Borrazzo, 2016); en este caso, las edades radiocarbónicas convencionales y calibradas son $1.364 \pm 34$ (D-AMS024407) (653-772 cal AD) y $970 \pm 24$ (D-AMS024408) (1.031-1.180 cal AD) (Sondeo 1 y Sondeo 2, respectivamente) [Calibraciones con dos sigmas, realizadas con la curva ShCal20 (Hogg et al. 2020) implementada en el programa Calib Rev.8.1.0 (Stuiver et al. 2020)].

En CC1 se recuperó, además de abundante material lítico, un total de 389 especímenes óseos, tanto en superficie como en estratigrafía (L'Heureux \& Borrazzo, 2016). El 80,9\% del material corresponde a Lama guanicoe, el 16,3\% a Mammalia y el 1,3\% a Ave. Se observó, también, la presencia de dos fragmentos de valva y una columela de Gasteropoda (L'Heureux \& Borrazzo, 2016). A partir del análisis de los centros de fusión tardía del conjunto óseo de guanaco, se observó que la presencia de individuos adultos (78,95\% > a 36 meses) y juveniles-subadultos (21,05\% entre 24 y 30 meses). Las clases de edad representadas sugieren que el área fue probablemente utilizada durante las estaciones de otoño y primavera. En el sitio se encuentran representados tanto elementos de la región axial (cráneo, vértebras, costillas), como apendicular (falange 1, carpos, tarsos y huesos largos), teniendo la mayor representación los huesos del basipodio, los cuerpos de vértebras lumbares y las epífisis proximales de fémur y radiocúbito y las distales de metapodios.

El estado de preservación del material óseo recuperado es, en general, heterogéneo. Las alteraciones tafonómicas más representadas en los huesos fueron la erosión por abrasión (51,4\%), la 
Tabla 2. CC1. Especímenes muestreados para análisis con MEB.

\begin{tabular}{ccccccccc}
\hline ID & $\begin{array}{c}\mathrm{N}^{\circ} \text { Muestra } \\
\text { MEB }\end{array}$ & Sondeo & $\begin{array}{c}\text { Nivel / Pro- } \\
\text { fundidad }(\mathrm{cm})\end{array}$ & Elemento & Porción & Lateralidad & $\begin{array}{c}\text { Fusión } \\
\text { epífisis }\end{array}$ & $\begin{array}{c}\text { Largo máxi- } \\
\text { mo }(\mathrm{mm})\end{array}$ \\
\hline 281 & 1 & 2 & NVIII $(40-45)$ & fémur & diáfisis & izquierdo & no & 87,99 \\
244 & 2 & 1 & NXII $(60-65)$ & húmero & diáfisis & indet. & indet. & 60,98 \\
$251^{*}$ & 3 & 1 & NXI $(55-60)$ & fémur & diáfisis & indet. & indet. & 45,55 \\
$284^{* *}$ & 4 & 2 & NVIII $(40-45)$ & metacarpo & diaf. px. & izquierdo & sí & 45,63 \\
290 & 5 & 2 & NVII $(35-40)$ & fémur & diaf. px. & izquierdo & no & 87,96 \\
317 & 6 & 2 & NIX (45-50) & hueso largo & diáfisis & indet. & indet. & 51,57 \\
\hline
\end{tabular}

Referencias: (*) nivel datado en $1.364 \pm 34$ años ${ }^{14} \mathrm{C}$ AP; $\left({ }^{* *}\right)$ espécimen datado en $970 \pm 24$ años ${ }^{14} \mathrm{C}$ AP; (indet.) indeterminado; (diaf. px.) diáfisis proximal.

actividad de radículas (31,9\%), la tinción con dióxido de manganeso (23,7\%) y la meteorización (73,3\%), aunque es posible que el porcentaje de esta última variable esté sobreestimado por razones que se expondrán más adelante. Se observó muy baja actividad de roedores y nula acción de carnivoros (L'Heureux \& Borrazzo, 2016). Las modificaciones antrópicas sólo se observaron sobre los restos de mamíferos, fundamentalmente fracturas y huellas de corte en los especímenes de guanaco, en tanto los restos de Mammalia aparecen con mayor frecuencia calcinados.

Se considera a CC1 un sitio de ocupaciones breves y recurrentes sucedidas durante el Holoceno tardío. Al estar sujeto a erosión, este locus expuso la mayor densidad de hallazgos arqueológicos para el área de Cancha Carrera. La evidencia disponible sugiere una subsistencia y una modalidad de explotación de la fauna asimilable a la observada en los sitios de estepa.

\section{MATERIALES Y MÉTODOS}

En primer término, se examinó la superficie de los huesos de guanaco recuperados en los sondeos estratigráficos. Las observaciones cualitativas se realizaron a ojo desnudo y mediante el uso de un microscopio digital Celestron 44308 PRO, con el objetivo de detectar modificaciones de interés, principalmente meteorización, remoción cortical, abrasión, marcas de raíces y restos radiculares aún adheridos a los especímenes. También se evaluó la friabilidad y pérdida de resistencia a la tracción de los huesos (Turner-Walker \& Parry, 1995) mediante la palpación de cada espécimen.
Para evaluar el estado de preservación histológica de los huesos, se seleccionaron seis muestras de huesos largos (hueso compacto) de guanaco procedentes de los dos sondeos estratigráficos (Tabla 2). La totalidad de las muestras seleccionadas provino de huesos sin alteración térmica, debido a los demostrados efectos de la temperatura sobre la estructura ósea como consecuencia de la pérdida de colágeno y la alteración de la bioapatita (v.gr. Gallo et al. 2021; Roberts et al. 2002). La muestra 3 (M3) proviene del nivel XI del Sondeo 1 datado en 1.364 \pm 34 años ${ }^{14} \mathrm{C}$ AP y la muestra 4 (M4) corresponde a una porción del elemento óseo recuperado en el Sondeo 2 datado en $970 \pm 24$ años ${ }^{14} \mathrm{C}$ AP. En los otros casos, el criterio de selección se basó en el tamaño del espécimen y el estado general del hueso, que necesita ser poco friable para resistir el pretratamiento y permitir su posterior observación mediante el uso de microscopía electrónica de barrido (MEB). Si bien la muestra es pequeña, la misma fue seleccionada de manera aleatoria respecto de su estado de preservación a nivel microestructural, dado que éste posee una baja correlación con el estado de preservación macroestructural visible a ojo desnudo (Galligani et al. 2019; Morales et al. 2018). Por esta razón, se espera que los resultados obtenidos sean suficientemente representativos de las principales tendencias a nivel del conjunto total, aunque esto deberá ser corroborado en futuros estudios.

Previo a la extracción de muestras aptas para observación con microscopía electrónica de barrido (MEB), se fotografió cada espécimen óseo a ser muestreado. Para la preparación de las muestras, se siguieron los pasos metodológicos (corte y limpieza) 

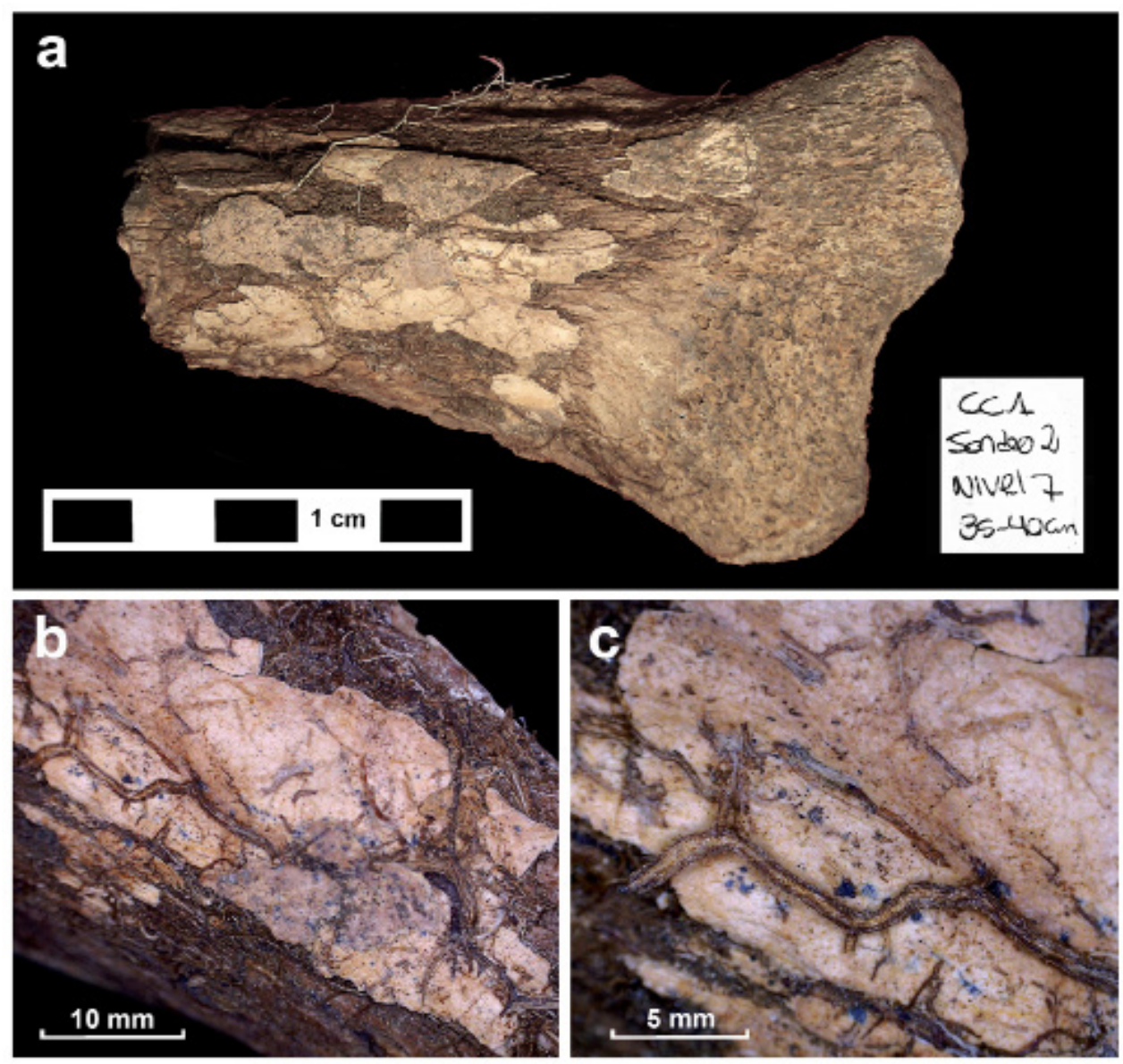

Fig. 5. CC1. a) Extremo proximal de diáfisis de fémur izquierdo de guanaco juvenil (cara anterior), recuperado en el Sondeo 2, Nivel 7 (35-40 cm) de CC1; se observa una extendida remoción cortical por acción de raicillas, aún presentes en el hueso conformando una red subsuperficial. b) Vista parcial del mismo elemento, con un detalle de la red de raicillas. c) Detalle de una de las raicillas; se observan manchas puntiformes por tinción con dióxido de manganeso $\left(\mathrm{MnO}_{2}\right)$

descritos en Morales y colaboradores (2018, pp. 784786), orientados a la obtención de superficies frescas sin pulir, capaces de proporcionar imágenes de alta calidad e interpretabilidad a bajo costo, medido en términos del tiempo y los recursos materiales invertidos en el proceso. Las observaciones se realizaron con dos microscopios diferentes: 1) Jeol JSM-6360LV, perteneciente al Servicio de Microscopía Electrónica de Barrido, Facultad de Ciencias Naturales y Museo, Universidad Nacional de La Plata y 2) FEI Quanta 200, acoplado a un sistema de microanálisis por espectroscopía de dispersión de energía de rayos X o EDS (Energy Dispersive X-Ray Spectroscopy), perteneciente al Laboratorio de Investigaciones de Metalurgia Física "Ing. Gregorio Cusminsky" (LIMF), Facultad de Ingeniería de la Universidad Nacional de La Plata. Ambos son microscopios ambientales, que trabajan a presión variable y bajo vacío, por lo que no fue necesario metalizar las muestras. Se utilizó un voltaje de aceleración típico, pero no exclusivo, de $10-20 \mathrm{keV}$ y una distancia de trabajo variable, principalmente situada entre 14 y $24 \mathrm{~mm}$. Las observaciones se realizaron con un detector de electrones retrodispersados, en modo composición y sombra, y con distintas magnificaciones (18x a $6000 \times$ ). En casos seleccionados, se obtuvieron espectros de composición química elemental de zonas específicas mediante EDS.

En esta etapa inicial de las investigaciones, se optó por un análisis exploratorio no cuantitativo, orientado a identificar parte del espectro de las alteraciones diagenéticas que constituyen una desviación respecto de la histología normal del hueso, a saber: a) macroporosidad (MaPo) $(>8,5 \mu \mathrm{m})$ y meso/microporosidad (Me/MiPO) 

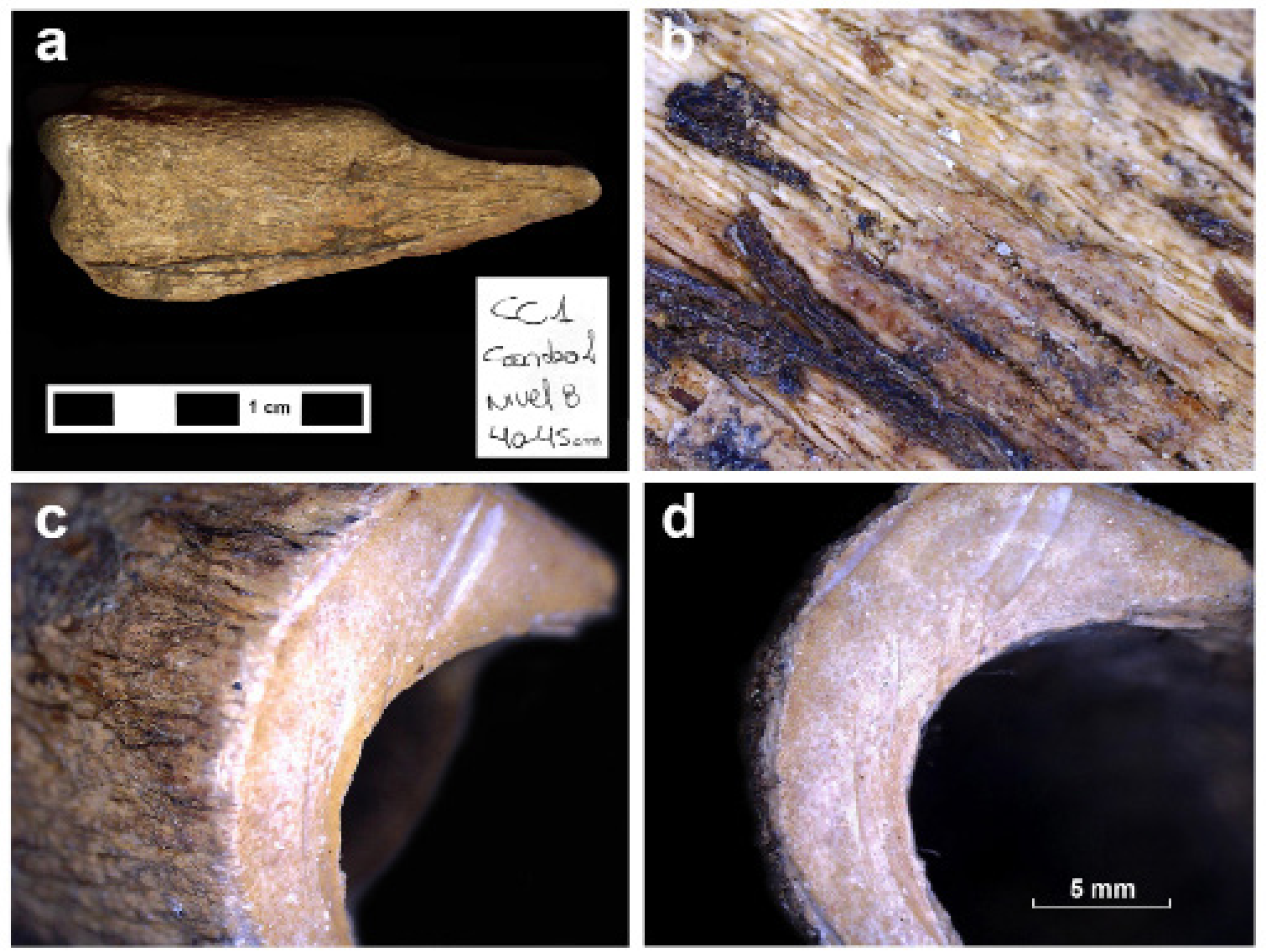

Fig. 6. CC1. a) Fragmento de diáfisis distal de fémur de guanaco muestreada para observaciones con MEB (fotografiada antes de efectuar el corte). b) Superficie del mismo espécimen, donde se observan raíces y surcos luego de la remoción de la superficie cortical por acción de las primeras. c-d) Vistas oblicua y frontal de la superficie fresca dejada por la extracción de la muestra para MEB (M1);

en ambos casos se observa la escasa profundidad $(<1 \mathrm{~mm})$ de la alteración diagenética de la superficie del hueso.

$(\leq 8,5 \mu \mathrm{m})$, b) presencia/ausencia de zonas discretas de porosidad espongiforme encerradas por un borde hipermineralizado (ZDPE), c) alteración del borde del canal de Havers $(\mathrm{ABCH})$ (i.e. normal, irregular, fragmentado); d) cementación de los osteones (CO), que describe la integridad de la línea de cemento o área hipermineralizada de contacto entre los sistemas de Havers (i.e. sí, no). En c y d se asignó un término descriptor distinto del normal si la condición se presentaba en al menos 10 osteones. Asimismo, se relevó la presencia/ausencia de elementos foráneos al hueso tales como framboides de pirita, rellenos minerales de los poros naturales y diagenéticos, microorganismos (v.gr. bacterias) o partes de microorganismos (v.gr. hifas, cuerpos fructíferos y esporas fúngicas; elementos radiculares de plantas) (ver Galligani et al. 2019; Morales et al. 2018).

\section{RESULTADOS}

Desde un punto de vista macroestructural, el conjunto óseo analizado se caracteriza por presentar una alta proporción de remoción cortical (con retención de islotes aislados de tejido superficial) y erosión por abrasión de los extremos epifisarios (en elementos fusionados) y de las epífisis y extremos diafisarios (en elementos no fusionados). Los huesos no son friables y presentan, en general, una buena resistencia a la tracción. Se detectan abundantes marcas de raíces y presencia de restos radiculares. Éstos se presentan aislados o agrupados conformando, en el último caso, una densa red superficial y subsuperficial (Fig. 5) que afecta a los sistemas circunferenciales externo (subperióstico) e interno (subendóstico) del tejido compacto de los huesos largos. La remoción de la capa cortical deja, en muchos casos, una superficie externa fibrosa, con numerosas raicillas 

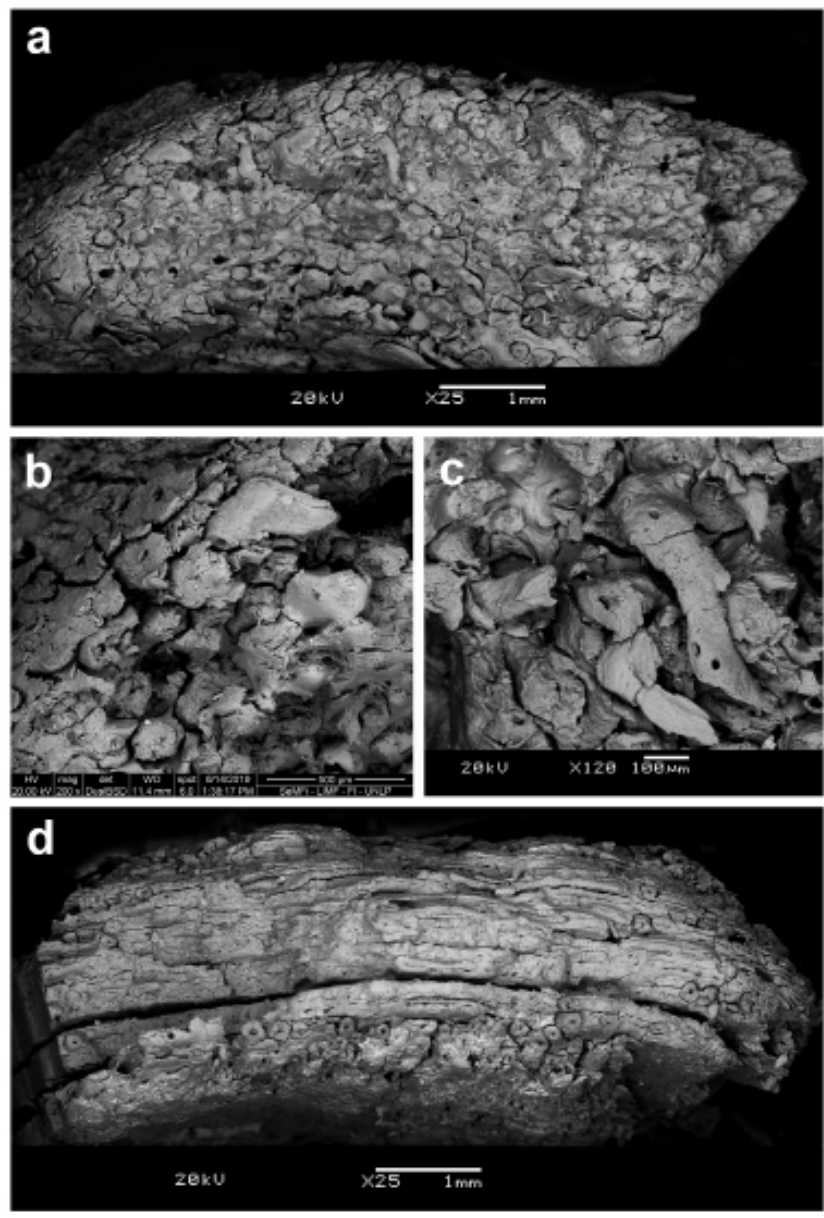

Fig. 7. Micrografías de cortes transversos de hueso de guanaco de CC1 observados con MEB. a-b) M1 (diáfisis distal de fémur). c) M5 (diáfisis proximal de fémur). d) M3 (fragmento de diáfisis de fémur). En todos los casos se observa la pérdida de cohesión de los osteones por presunta disolución de las líneas de cemento y lamelas intersticiales. En d se observan, además, fisuras concéntricas en los tres cuartos de espesor total ocupados por hueso plexiforme (individuo juvenil).

Tabla 3. CC1. Resultados de las observaciones realizadas con el uso de microscopía electrónica de barrido.

\begin{tabular}{ccccccccc}
\hline $\mathrm{N}^{\circ}$ Muestra & MaPo & Me/MiPo & ZDPE & $\mathrm{ABCH}$ & $\mathrm{CO}$ & Raicillas & Hifas & Otras Inclusiones \\
\hline 1 & no & sí & no & frag. & no & sí & no & no \\
2 & no & sí & no & irreg. & no & sí & no & no \\
3 & sí & sí & no & frag. & sí & sí & sí & sí \\
4 & sí & sí & sí & frag. & sí & sí & sí & no \\
5 & no & sí & no & irreg. & no & $?$ & no & no \\
6 & sí & sí & sí & frag. & sí & sí & sí & no \\
\hline
\end{tabular}

Referencias: (MaPo) macroporosidad; (Me/MiPo) meso/microporosidad; (ZDPE) zonas discretas de porosidad espongiforme encerradas por un borde hipermineralizado; $(\mathrm{ABCH})$ alteración del borde del canal de Havers; $(\mathrm{CO})$ cementación de los osteones; (frag.) fragmentado; (irreg.) irregular; (?) desconocido. 

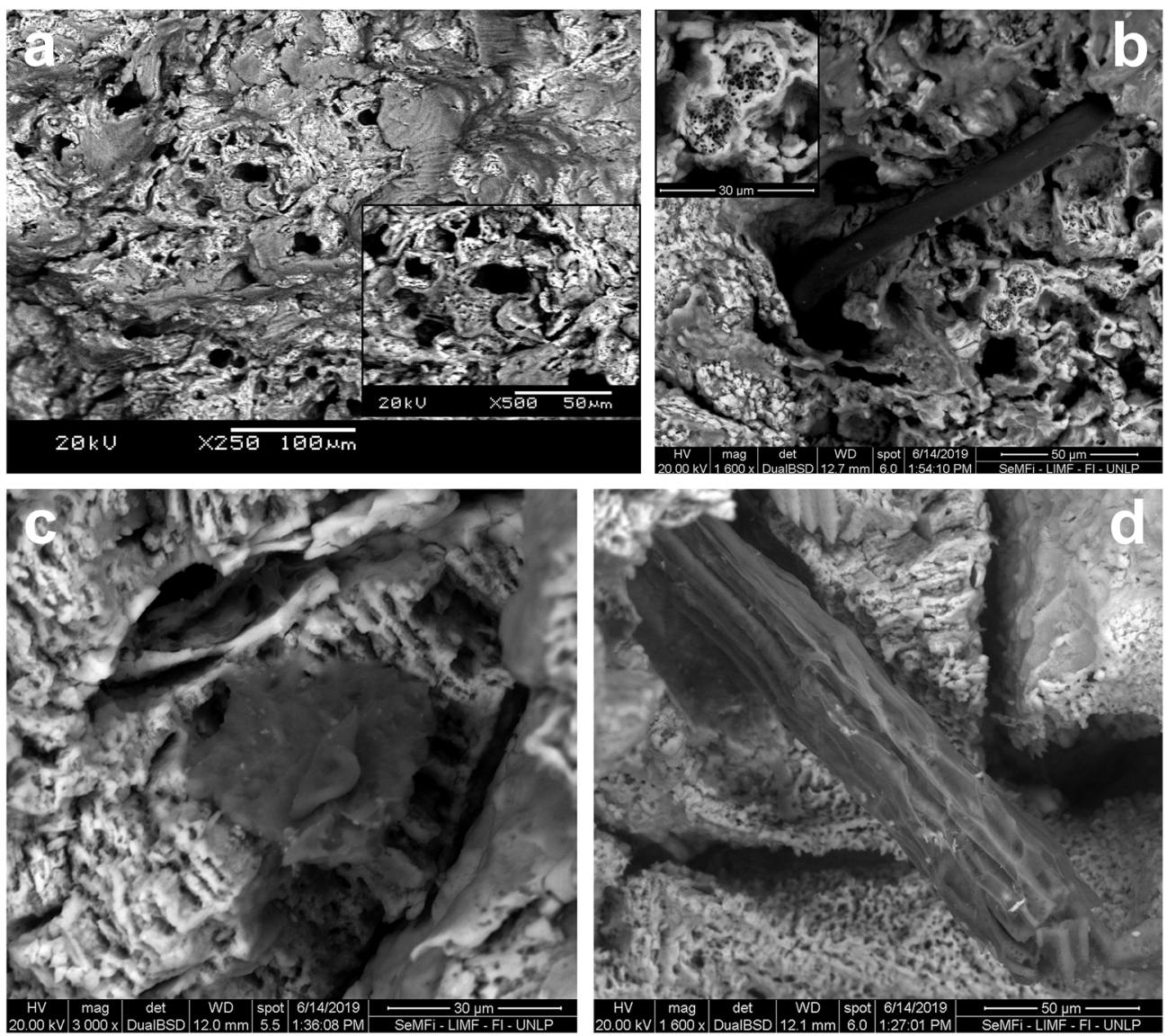

Fig. 8. Micrografías de cortes transversos de hueso de guanaco de CC1 observados con MEB. a-b) Ejemplos de zonas discretas de porosidad espongiforme encerradas por un borde hipermineralizado (ZDPE) en M4 (diáfisis proximal de metacarpo) y M6 (diáfisis de hueso largo), respectivamente; en b se observa, también, una hifa asomando del único canal de Havers que se visualiza en la imagen. c-d) Ejemplos de raicillas en M1 (diáfisis distal de fémur); en el primer caso atravesando un osteón en sentido longitudinal y, en el segundo, asomando de un canal de Havers.

dispuestas a lo largo de los surcos longitudinales. En los casos en los que se pudo disponer de una sección transversal fresca (v.gr. huesos muestreados para análisis microscópico), se pudo verificar que la rugosidad penetra muy poco en el tejido compacto. En el caso del ejemplo de la Fig. 6, correspondiente al mismo espécimen de donde se extrajo la muestra 1 para ser observada con MEB, el espesor promedio de la capa alterada es de alrededor de $0,5 \mathrm{~mm}$, con un máximo inferior a $1 \mathrm{~mm}$.

Desde un punto de vista microestructural (Tabla 3), la totalidad de las muestras presenta meso/ microporosidad mientras que sólo la mitad posee macroporosidad. Con excepción de M4 y M6, las muestras presentan una pérdida de cementación entre los osteones por afectación de la línea de cemento y de las lamelas intersticiales, lo que le confiere al tejido un aspecto "desmigajado" (Fig. 7). En dos casos (M4 y M6, procedentes respectivamente de los niveles estratigráficos 8 y 9 del Sondeo 2) se registra la presencia de numerosas zonas discretas de porosidad espongiforme rodeada por un anillo hipermineralizado (Figs. 8a y b). Los contornos de los canales de Havers se encuentran alterados en todas las muestras, primando la fragmentación del borde. Cinco muestras presentan raicillas; en el caso restante (M5), la determinación es dudosa por cuanto la morfología es diferente a los demás casos, aunque su diámetro es superior al esperado para las hifas (i.e. $>5 \mu \mathrm{m}$ ). Las raicillas penetran e invaden el tejido compacto a diferentes profundidades, ocupando tanto los canales de Havers como los canalículos y 
lagunas (Figs. 8c y d). Tres muestras (M3, M4 y M6) presentan hifas (Fig. 8b). En una muestra (M3), se detectó un objeto indeterminado en el interior de un canal de Havers; se realizó un espectro EDS del mismo, que no arrojó una composición elemental incompatible con la del hueso. En una muestra (M3), se registraron fisuras concéntricas en el tejido plexiforme de un fragmento de diáfisis de fémur de un individuo probablemente juvenil (Fig. 7d).

\section{DISCUSIÓN}

A nivel macroestructural, los huesos de guanaco depositados y enterrados en un presunto molisol en CC1 se caracterizan por presentar modificaciones extensivas de su superficie, como resultado de la acción de raíces y de erosión por abrasión, esta última probablemente promovida por la textura francoarenosa de la matriz edáfica. Las raíces penetran a través de forámenes, fisuras y fracturas, generando una densa red que invade las capas subsuperficiales a diferentes profundidades del tejido compacto. Esto provoca la remoción parcial o total del tejido cortical, exponiendo una superficie rugosa con extensos surcos longitudinales que puede, en ocasiones, ser confundida con la resultante de un estadio intermedio de meteorización. En el caso de CC1, los perfiles de meteorización informados preliminarmente por L'Heureux \& Borrazzo (2016) deben ser revisados, ya que se detectaron especímenes en los cuales se verifica la confusión mencionada precedentemente.

El notable aumento de la porosidad a distintos niveles (i.e. macro y meso/micro) observado con el uso de MEB, así como la pérdida de cohesión de los osteones por afectación de las líneas de cemento y de las lamelas intersticiales, sugiere la acción conjunta de dos procesos principales: la disolución mineral y el ataque microbiano (Hedges, 2002; Smith et al. 2007; Turner-Walker et al. 2002). Entre los factores coadyuvantes para que tengan lugar ambos procesos están la permeabilidad y aireación de la matriz edáfica -favorecidas por la textura franco-arenosa del suelo-, el régimen hidrológico de recarga inferido para el sitio y los valores de $\mathrm{pH}$ medianamente ácidos registrados (Hedges, 2002; Hedges \& Millard, 1995; Kendall et al. 2018; Nielsen-Marsh et al. 2007; TurnerWalker, 2012, 2019). Es significativa la presencia, en al menos dos especímenes, de zonas discretas de porosidad espongiforme encerradas por un borde hipermineralizado (ZDPE), que constituyen rasgos altamente diagnósticos de actividad bacteriana (Jans, 2008, 2014; Jans et al. 2004; Turner-Walker, 2012, 2019; Turner-Walker \& Jans, 2008; Turner-Walker et al. 2002). Evidencia similar fue encontrada por Chadefaux (2006, p. 44, en Legoupil, 2009) en un espécimen proveniente de la unidad sedimentaria IV de Cerro Castillo, Última Esperanza.

El aumento de la porosidad puede, a su vez, incrementar la adsorción y retención de agua por parte del hueso (Hedges, 2002; Kendall et al. 2018). Esto contribuye, por un lado, a aumentar la reactividad del hueso potenciando la pérdida de mineral (Kendall et al. 2018) y, por el otro, puede convertir a los huesos en atractores de la actividad radicular de las plantas. En CC1, esta última está ampliamente documentada, tanto a nivel macroscópico como microscópico. Como fuera mencionado, las raíces ejercen una doble acción sobre los huesos: física, ocasionando la ruptura del tejido por presión de turgencia (Gabet et al. 2003; Pokines \& Baker, 2014) y química, a través de la secreción de compuestos ácidos que pueden contribuir a la disolución mineral (Koo et al. 2005; Pokines \& Baker, 2014). Las hifas, por su parte, parecen no afectar significativamente a los huesos de manera física o química, utilizándolas más como un medio que como una fuente de nutrientes (ver discusiones recientes en Galligani et al. 2019; Kendall et al. 2018; Morales et al. 2018; TurnerWalker, 2012, 2019).

Tanto la disolución mineral como el ataque microbiano tienen, como consecuencia, la degradación y pérdida de colágeno (Smith et al. 2007), debido a que este último proceso obedece tanto a causas químicas (hidrólisis química) como biológicas (hidrólisis enzimática por colagenasas bacterianas) (Child, 1995; Collins et al. 1995; Smith et al. 2002, 2007). Si bien hasta el presente no se cuenta, para $\mathrm{CC} 1$, con información cuantitativa acerca del contenido y calidad del colágeno óseo, evidencia circunstancial sugiere que el proceso de pérdida de colágeno -aunque no necesariamente su degradación- no avanzó aún lo suficiente como para comprometer severamente la integridad de los huesos. En efecto, en los elementos óseos analizados se observa: a) ausencia de friabilidad y una buena resistencia a la tracción, b) un fuerte olor a materia orgánica quemada al ser sometidos a la fricción con elementos cortantes ( $v$.gr. en ocasión de la extracción de muestras) y c) una frecuencia relativa 


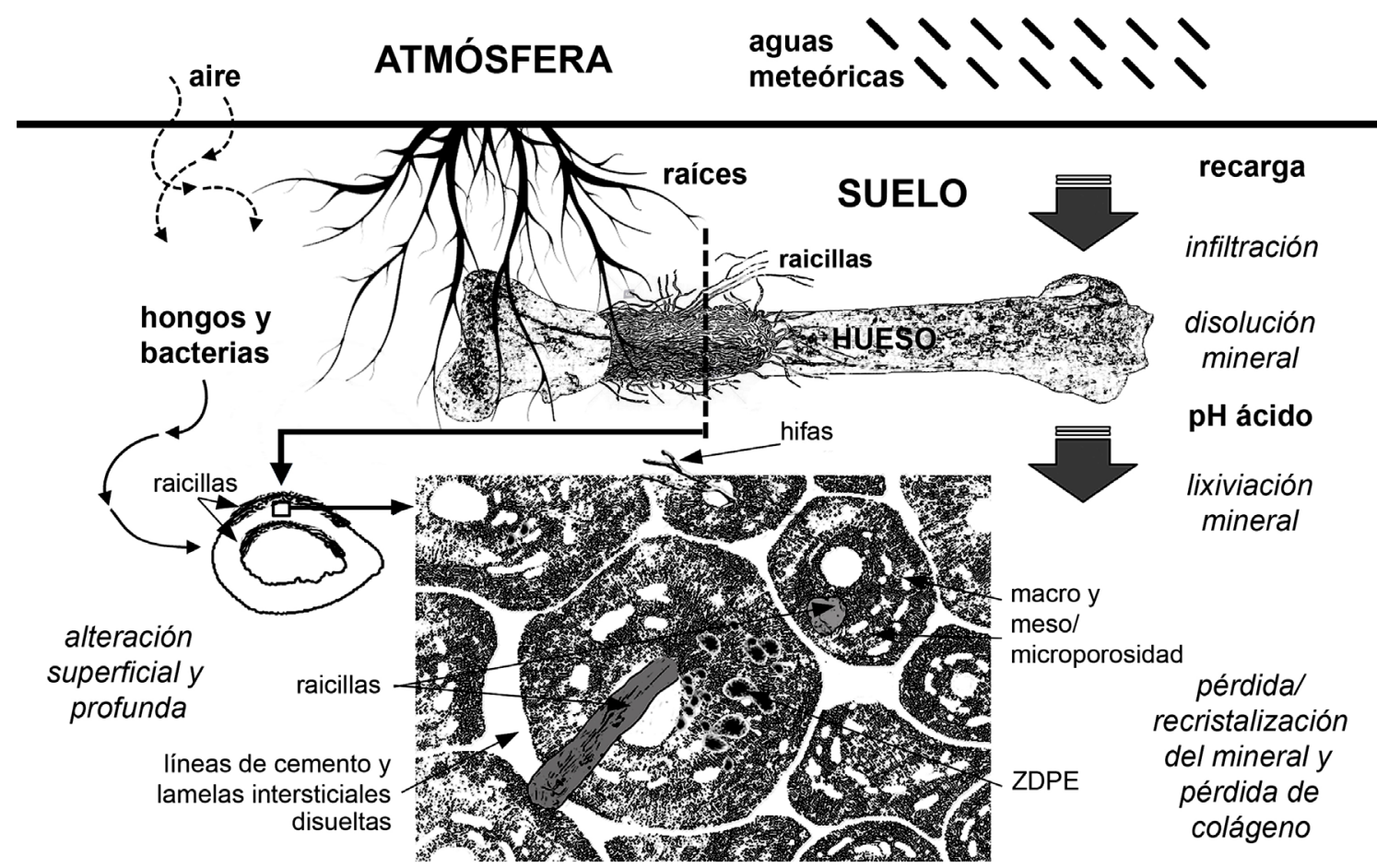

Fig. 9. Representación esquemática de las principales modificaciones diagenéticas observadas

en el conjunto óseo proveniente de los sondeos de CC1, así como de los probables factores (en negritas) y procesos (en itálica) inferidos a partir de tales observaciones.

del $100 \%$ de éxito en la realización de dataciones radiocarbónicas. Sin embargo, si bien el estado de conservación de los huesos de este sitio es regular, la expectativa a largo plazo (en el orden de los pocos miles de años), es la de su total destrucción bajo condiciones de enterramiento (i.e. sin contar su reexposición a los agentes de superficie por la erosión retrocedente de la barranca).

Un resumen de los aspectos más sobresalientes observados en el conjunto óseo proveniente de los sondeos de CC1, así como de los procesos inferidos a partir de tales observaciones, se encuentra expresado en la Fig. 9.

En términos generales, la evidencia procedente de $\mathrm{CC} 1$ se encuentra en concordancia con las expectativas derivadas de nuestro modelo de preservación ósea diferencial en relación con los suelos. Esta evaluación inicial del modelo requiere ser replicada en otras localizaciones, tanto cercanas como lejanas, así como extendida a otras especies, principalmente al huemul (Hippocamelus bisulcus), el otro mamífero de gran tamaño explotado en los bosques patagónicos (Fernández et al. 2015, 2016).
Datos recientes provenientes de sitios a cielo abierto y bajo bloques en la zona del Chaltén (Belardi et al. 2020b) y del río Penitente (Belardi et al. 2020a) parecen ajustarse a las predicciones del modelo, por cuanto en ambos casos se han registrado condiciones de preservación relativamente buenas en conjuntos óseos enterrados en probables Molisoles o Aridisoles, en sectores con presencia de bosque $\mathrm{u}$ ocupados hasta el pasado reciente por ñirantales. Resta aún muestrear más intensivamente aquellos sectores en los que se espera pobre o nula preservación ósea debido a la presencia de Andisoles, Inceptisoles y Espodosoles, típicamente dominados por bosques de lenga.

La evaluación futura del modelo deberá tener en cuenta, sin embargo, una posibilidad: que aquellas áreas con menores probabilidades de preservación ósea coincidan con aquellas con menores probabilidades de haber sido visitadas, explotadas u ocupadas en el pasado, debido a que se encuentran ubicadas más hacia el interior del bosque, a mayor altitud y con mayor pendiente. De igual modo, la zona que presenta mejores condiciones para la 


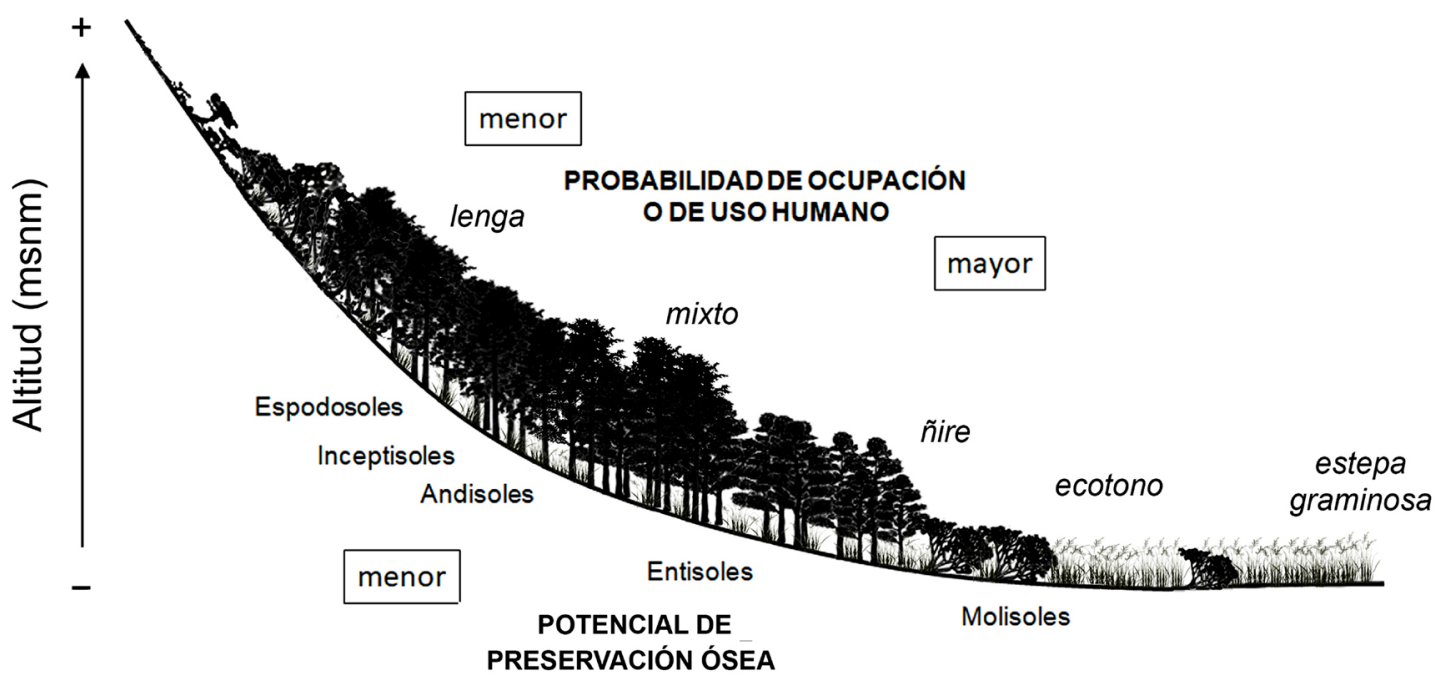

mayor

Oeste

Este

Fig. 10. Potencial de preservación ósea de los huesos en función del nivel inferido de corrosividad (sensu Nielsen-Marsh et al. 2007) de los suelos en los bosques de lenga y ñire de Patagonia meridional versus las probabilidades de ocupación o uso humanos del bosque. Modificado a partir de la Fig. 2.

preservación a largo plazo de los huesos -asociada con suelos químicamente poco agresivos, con terrenos menos escarpados y con ñirantales-, puede coincidir con aquella zona probablemente más transitada o utilizada del bosque, es decir, la más cercana al ecotono con la estepa. En este caso, habría buenas chances de localizar conjuntos arqueofaunísticos que registraran dicha actividad, en el caso que ésta hubiera sido frecuente o localmente intensa (Fig. 10). Esta expectativa podría ser válida, al menos, para ocupaciones correspondientes al Holoceno tardío. Para momentos anteriores, las bajas probabilidades de registrar ocupaciones se distribuirían más o menos uniformemente en relación con los tipos de suelos $y$ formaciones de bosque.

\section{CONSIDERACIONES FINALES}

La investigación descrita en este trabajo constituye un primer intento de abordar, tanto desde un punto de vista teórico como empírico, el problema de la preservación ósea en sitios a cielo abierto localizados en ambientes de bosque deciduo en Patagonia meridional. El modelo de preservación ósea diferencial propuesto, basado en las propiedades de los suelos, deberá ser puesto a prueba con evidencia procedente de diversas localizaciones. En este sentido, se espera que constituya un marco que oriente la investigación, proporcionando un criterio de estratificación claro que permita la realización de muestreos aleatorios y dirigidos, tendientes a la detección de conjuntos arqueofaunísticos en el bosque. Esto constituirá, sin dudas, un aporte necesario para la discusión informada acerca de la intensidad y patrones de uso prehistórico de esta ecorregión, en gran medida desconocida aún desde un punto de vista arqueológico.

\section{AGRADECIMIENTOS}

A Luis Alberto Borrero por permitir el acceso a las muestras de CC1. A Juan Bautista Belardi por la lectura atenta del manuscrito y por sus invaluables observaciones y sugerencias. La presente investigación se financió con fondos de los proyectos dirigidos por L. A. Borrero (UBACyT 20020100100957; PIP-11220110100262) y G. L. L'Heureux (PICT 2014-2061; PICT 2019-02106). 


\section{BIBLIOGRAFÍA}

Alberdi, M. (1995). Ecofisiología de especies leñosas de los bosques hidrófilos templados de Chile: resistencia a la sequía y bajas temperaturas. En J. Armesto, C. Villagrán y C. Arroyo (Eds.), Ecología de los Bosques Nativos de Chile (pp. 279-299). Universidad de Chile.

Anderson, M. P., Woessner, W. W., y Hunt, R. J. (2015). Applied Groundwater Modeling. Simulation of Flow and Advective Transport (2da ed.). Academic Press.

Arrigoni, G. (1991). Interpretación de la ocupación del alero del Chamán. Shincal, 3, 216-220.

Arrigoni, G., y Fernández, P.M. (2004). Los restos óseos del Alero del Sendero de Interpretación: integridad, resolución y aprovechamiento de los recursos faunísticos del bosque. En M.T. Civalero, P.M. Fernández y A.G. Guráieb (Comps.), Contra Viento y Marea. Arqueología de Patagonia (pp. 403-415). Sociedad Argentina de Antropología e Instituto Nacional de Antropología y Pensamiento Latinoamericano.

Aschero, C., Goñi, R., Civalero, T., Molinari, R., Espinosa, S., Guráieb, G., y Bellelli, C. (2005). Holocenic park: arqueología del parque nacional Perito Moreno. Anales de Parques Nacionales, 17, 71-119.

Barberena, R. (2002). Los Límites del Mar. Isótopos Estables en Patagonia Meridional. Sociedad Argentina de Antropología.

Barrientos, G., Goñi, R., Zangrando, F. A., Del Papa, M., García Guraieb, S., Arregui, M. J., y Negro, C. (2007). Human taphonomy in southern Patagonia: a view from the Salitroso lake basin (Santa Cruz, Argentina). En M. Gutiérrez, L. Miotti, G. Barrientos, G. Mengoni Goñalons y M. Salemme (Eds.), Taphonomy and Zooarchaeology in Argentina (pp. 187-201). BAR International Series 1601, Archaeopress.

Belardi, J. B., y Caracotche, S. (2005). Resultados arqueológicos en el noroeste del lago Viedma, Provincia de Santa Cruz. En E. Berberián (Ed.), Actas del XIII Congreso Nacional de Arqueología Argentina (pp. 81-88). Editorial Brujas.

Belardi, J. B., y Carballo Marina, F. (2003). Tafonomía regional en la cuenca media del río Coyle (Santa Cruz, Patagonia Argentina). Intersecciones en Antropología, 4, 59-73.

Belardi, J.B., y Carballo Marina, F. (2014). La señal arqueológica del interior del bosque en la margen sur del lago San Martín (provincia de Santa Cruz). Comechingonia. Revista de Arqueología, 18, 181-202.

Belardi, J. B., Carballo Marina, F., y Borrero, L. A. (2020a). Circulación humana durante el Holoceno tardío en el bosque y ecotono bosque-estepa: el curso inferior del río Penitente (suroeste de Santa Cruz). Revista del Museo de Antropología, 13(3), 321-334.

Belardi, J. B., Carballo Marina, F., y Espinosa, S. (Eds.) (2006).
La Cuenca del Río Coyle. Estado Actual de las Investigaciones. UNPA.

Belardi, J.B., Espinosa, S.L., Carballo Marina, F., y Blanco, R.V. (2020b). Al pie del cerro Fitz Roy: cazadores recolectores en el noroeste del lago Viedma, provincia de Santa Cruz. Revista del Museo de Antropología, 13(3), 295-306.

Belardi, J. B., Bregliani, M., Rindel, D., Bourlot, T. J., y Gómez, H. (2007). Condiciones de preservación de conjuntos arqueofaunísticos en la meseta del Strobel (provincia de Santa Cruz, Argentina). En F. Morello, M. Martinic, A. Prieto y G. Bahamonde (Eds), Arqueología de Fuego Patagonia. Levantando Piedras, Desenterrando Huesos... y Develando Arcanos (pp. 411-419). Ediciones CEQUA.

Berna, F., Matthews, A., y Weiner, S. (2004). Solubilities of bone mineral from archaeological sites: the recrystallization window. Journal of Archaeological Science, 31(7), 867-882.

Bocherens, H., Tresset, A., Wiedemann, F., Giligny, F., Lafage, F., Lanchon, Y., y Mariotti, A. (1997). Bone diagenetic evolution in two french neolithic sites. Bulletin de la Société Géologique de France, 168(5), 555-564.

Borella, F. (2004). Tafonomía Regional y Estudios Arqueofaunísticos de Cetáceos en Tierra del Fuego y Patagonia Meridional. BAR International Series 1257, Archaeopress.

Borrazzo, K., y Borrero, L. A. (Eds.). (2011). Bosques, Montañas y Cazadores: Investigaciones Arqueológicas en Patagonia Meridional. CONICET-IMHICIHU.

Borrero, L. A. (1994-1995). Arqueología de Patagonia. Palimpsesto, 4, 9-69.

Borrero, L. A. (Ed.). (1998). Arqueología de la Patagonia Meridional (Proyecto Magallania). Concepción del Uruguay, Ediciones Búsqueda de Ayllu.

Borrero, L. A. (2001). Regional taphonomy: background noise and the integrity of the archaeological record. En L. Kuznar (Ed.), Ethnoarchaeology of Andean South America. Contributions to Archaeological Method and Theory (pp. 243-254). International Monographs in Prehistory.

Borrero, L. A. (2007). No direction home. Vertebrate taphonomy in Argentina. En M.A. Gutiérrez, L. Miotti, G. Barrientos, G. Mengoni Goñalons y M. Salemme (Eds.), Taphonomy and Zooarchaeology in Argentina (pp. 4-9). BAR International Series 1601, Archaeopress.

Borrero, L.A. (2012-2015). Delimitación espacial del núcleo poblacional arqueológico patagónico occidental. Proyecto UBACyT 20020100100957. MS.

Borrero, L. A., y Charlin, J. (Eds.). (2010). Arqueología de Pali Aike y Cabo Vírgenes (Santa Cruz, Argentina). Dunken.

Borrero, L. A., y Muñoz, A. S. (1999). Tafonomía en el bosque patagónico: implicaciones para el estudio de su explotación y uso por poblaciones de cazadores recolectores. 
En Soplando en el Viento. Actas III Jornadas de Arqueología de la Patagonia (pp. 43-56). INAPL y Universidad Nacional del Comahue.

Borrero, L. A., Franco, N. V., Martin, F. M., Barberena, R., Guichón, R., Belardi, J. B., Favier Dubois, C., y L'Heureux, G. L. (2006). Las cabeceras del Coyle: información arqueológica y circulación de poblaciones humanas. En J.B. Belardi, F. Carballo Marina y S. Espinosa (Eds.), La Cuenca del río Coyle. Estado Actual de las Investigaciones (pp. 75-95). Universidad Nacional de la Patagonia Austral.

Bottari, C., y Valiza Davis, C. (2019). Los restos óseos del sitio arqueológico La Mesada (meseta central de Santa Cruz): una aproximación tafonómica. Comechingonia, Revista de Arqueología, 23(2), 111-133.

Buol, S. W., Southard, R. J., Graham, R. C., y McDaniel, P. A. (2011). Soil Genesis and Classification (6ta ed.). John Wiley y Sons.

Cabrera, A. L. (1976). Regiones fitogeográficas argentinas. En W. F. Kugler (Ed.), Enciclopedia Argentina de Agricultura y Jardinería (pp. 1-85). Tomo 2, Fascículo 1. Acme.

Carballo Marina, F., Belardi, J. B., y Borrero, L. A. (2016). Nuevos datos para la discusión arqueológica de corredores en el bosque del suroeste de la provincia de Santa Cruz, Argentina: el caso del Arroyo Los Loros. Magallania, 44(2), 209-217.

Carrasco, J. F., Casassa, G., y Rivera, A. (1998). Climatología actual del campo de hielo sur y posibles cambios por el incremento del efecto invernadero. Anales del Instituto de la Patagonia, 26, 119-128.

Carrasco, J. F., Casassa, G., y Rivera, A. (2003). Meteorological and climatological aspects of the southern Patagonia icefield. En The Patagonian Icefields: A Unique Natural Laboratory for Environmental and Climate Change Studies (pp. 29-42). Centro de Estudios Científicos.

Castro, A., Moreno, E., Andolfo, M., Giménez, R., Peña, C., Mazzitelli, L., Zubimendi, M., y Ambrústolo, P. (2003). Análisis distribucionales en la costa de Santa Cruz (Patagonia Argentina): alcances y resultados. Magallania, 31, 69-94.

Chadefaux, C. (2006). Altérations Physico-Chimiques des Matériaux Archéologiques (tesis de Master de Chimie). Centre de Recherche et de Restauration des Musées de France, Université Pierre et Marie Curie, Paris.

Child, A. M. (1995). Towards and understanding of the microbial decomposition of archaeological bone in the burial environment. Journal of Archaeological Sciences, 22, 165-174.

Collins, M. J., Riley, M., Child, A., y Turner-Walker, G. (1995). A basic mathematical simulation of the chemical degradation of ancient collagen. Journal of Archaeological Science, 22, 175-183.

Collins, M. J., Nielsen-Marsh, C. M., Hiller, J., Smith, C. I.,
Roberts, J. P., Prigodich, R. V., Wess, T. J., Csapò, J., Millard, A. R., y Turner-Walker, G. (2002). The survival of organic matter in bone: a review. Archaeometry, 44(3), 383-394.

Cruz, I. (2003). Paisajes Tafonómicos de Restos de Aves en el Sur de Patagonia Continental. Aportes para la Interpretación de Conjuntos Avifaunísticos en Registros Arqueológicos del Holoceno (tesis doctoral inédita). Facultad de Filosofía y Letras, Universidad de Buenos Aires, Buenos Aires.

Cruz, I. (2015). Las investigaciones sobre preservación de huesos de aves y mamíferos grandes en Patagonia (Argentina). Archaeofauna, 24, 209-224.

Cruz, I., y Caracotche, M. S. (2006). Arqueología de la Costa Patagónica. Perspectivas para la Conservación. Universidad Nacional de la Patagonia Austral, Subsecretaría de Cultura de la Provincia de Santa Cruz.

Cruzate, G., Gómez, L., Pizarro, M. J., Mercuri, P., y Banchero, S. (2007). Suelos de la República Argentina. SAGyP - INTA - Proyecto PNUD ARG/85/019.

De Angelis, H. H., y Belardi, J. B. (Eds.). (2020). Dossier: Cazadores recolectores en el bosque de Patagonia y Tierra del Fuego: nuevos datos, patrones y modelos. Revista del Museo de Antropología, 13(3), 249-364.

De Niro, M.J. (1985). Postmortem preservation and alteration of in vivo bone collagen isotope ratios in relation to palaeodietary reconstruction. Nature, 317, 806-809.

Dimitri, M. (1972). La región de los bosques andino-patagónicos. En Colección Científica del INTA. Tomo 10 (pp. 1478). INTA.

Dube, F., Zagal, E., Stolpe, N., y Espinosa, M. (2009). The influence of land-use change on the organic carbon distribution and microbial respiration in a volcanic soil of the Chilean Patagonia. Forest Ecology and Management, 257, 1695-1704.

Emperaire, J., y Laming, A. s.f. Note de Travail, Route de Cerro Castillo à Rio Paine. Archives Emperaire doc. $n^{\circ} 58$, dactilografiado.

Escobar, F., Vidal, F., Garin, F., y Naruse, R. (1992). Water balance in the Patagonia icefield. En R. Naruse y M. Anya (Eds.), Glaciological Researches in Patagonia 1990 (pp. 109-119). Japanese Society of Snow and Ice.

Espinosa, S., Belardi, J. B., y Súnico, A. (2009). ¿Cuán al oeste? Arqueología del istmo de la península Maipú (lago San Martín, provincia de Santa Cruz) en su contexto regional. Arqueología, 15, 187-207.

Fernández, P. M., Cruz, I., Belardi, J.B., De Nigris, M., y Muñoz, S. A. (2015). Human predation and natural history of huemul (CERVIDAE; Hippocamelus bisulcus Molina) in Patagonia: a zooarchaeological analysis. Journal of Ethnobiology, 35(3), 472-498. 
Fernández, P. M., Cruz, I., Belardi, J. B., De Nigris, M., y Muñoz, S. A. (2016). La explotación de huemul (Hippocamelus bisulcus, Molina 1782) en la Patagonia a lo largo del Holoceno. Magallania, 44(1), 187-209.

Franco, N. V. (2002). Estrategias de Utilización de Recursos Líticos en la Cuenca Superior del río Santa Cruz (tesis doctoral inédita). Facultad de Filosofía y Letras, Universidad de Buenos Aires, Buenos Aires.

Gabet, E. J., Reichman, O. J., y Seabloom, E. W. (2003). The effects of bioturbation on soil processes and sediment transport. Annual Review of Earth and Planetary Sciences, 31, 249-273.

Galligani, P. E. (2020). Preservación Ósea Diferencial en un Ambiente Subtropical del Centro-Este de Argentina: Tafonomía Regional en Perspectiva Arqueológica. BAR International Series 3003. BAR Publishing. http://doi. org/10.30861/9781407357300.

Galligani, P. E., Sartori, J. I., y Barrientos, G. (2019). Bacterial bioerosion in human and animal bones from subtropical environments (northern Pampa/middle Paraná river basin, República Argentina). Journal of Archaeological Science: Reports, 25, 561-574. http://doi.org/10.1016/j. jasrep.2019.05.015.

Gallo, G., Fyhrie, M., Paine, C., Ushakov, S. V., Izuho, M., Gunchinsuren, B., Zwyns, N., y Navrotsky, A. (2021). Characterization of structural changes in modern and archaeological burnt bone: Implications for differential preservation bias. PLoS ONE, 16, e0254529. http:// doi.org/10.1371/journal.pone.0254529.

Gargaglione, V., González Polo, M., y Peri, P.L. (2017). Microorganismos del suelo en bosques de ñire en Patagonia sur. Resultados preliminares. Ciencia e Investigación Forestal, 23(2), 19-28.

Gargaglione, V., Bahamonde, H., y Peri, P.L. (2018). Decomposition and nutrient release of grass and tree fine roots along an environmental gradient in southern Patagonia. Austral Ecology, 44, 276-289.

Garreaud, R. D., Vuille, M., Compagnucci, R., y Marengo, J. (2009). Present-day South American climate. Palaeogeography, Palaeoclimatology, Palaeoecology, 281, 180-195.

González Polo, M., Fernández-Souto, A., y Austin, A. T. (2013). Coarse woody debris stimulates soil enzimatic activity and litter decomposition in an old growth temperate forest of Patagonia, Argentina. Ecosystems, 16, 1025-1038.

Goñi, R. (2010). Cambio Climático y Poblamiento Humano durante el Holoceno Tardío en Patagonia Meridional. Una Perspectiva Arqueológica (tesis doctoral inédita). Facultad de Filosofía y Letras, Universidad de Buenos Aires, Buenos Aires.
Gradín, C. (1980). Secuencias radiocarbónicas del sur de la Patagonia argentina. Relaciones de la Sociedad Argentina de Antropología (N.S.), 14, 177-194.

Guadelli, J. L. (2008). La gélifraction des restes fauniques. Expérimentation et transfert au fossile. Annales de Paléontologie, 94, 121-165.

Guadelli, J. L. (2015). La gélifraction des restes fauniques. Du laboratoire au terrain. En M. Balasse, J. P. Brugal, Y. Dauphin, E. M. Geigl, C. Oberlin e I. Reiche (Eds.), Messages d'Os: Archéométrie du Squelette Animal et Humain (pp. 177186). Editions des Archives Contemporaines.

Hedges, R. E. M. (2002). Bone diagenesis: an overview of processes. Archaeometry, 44, 319-328.

Hedges, R. E. M., y Millard, A. R. (1995). Bones and groundwater: towards the modelling of diagenetic processes. Journal of Archaeological Science, 22, 155-164.

Hedges, R. E. M., Millard, A. R., y Pike, A. W. G. (1995). Measurements and relationships of diagenetic alteration of bone from three archaeological sites. Journal of Archaeological Science, 22, 201-209.

Hedges, R. E. M., Clement, J. G., Thomas, C. D. L., y O'Connell, T. C. (2007). Collagen turnover in the adult femoral mid-shaft: modeled from anthropogenic radiocarbon tracer measurements. American Journal of Physical Anthropology, 133(2), 808-816.

Henderson, J. (1987). Factors determining the state of preservation of human remains. En A. Boddington, A. N. Garland y R. C. Janaway (Eds.), Death, Decay, and Reconstruction: Approaches to Archaeology and Forensic Science (pp. 43-54). Manchester University Press.

Herrera, O. (1988). Arqueofauna del sitio Cerro Casa de Piedra 5. En Resúmenes del IX Congreso Nacional de Arqueología Argentina. Facultad de Filosofía y Letras, Universidad de Buenos Aires, Buenos Aires.

Hogg, A., Heaton, T., Hua, Q., Palmer, J., Turney, C., Southon, J., Bayliss, A., Blackwell, P. G., Boswijk, G., Bronk Ramsey, C., Pearson, C., Petchey, F., Reimer, P., Reimer, R., y Wacker, L. (2020). SHCal20 Southern Hemisphere calibration, 0-55,000 years cal BP. Radiocarbon, 62(4), 759-778. http://doi.org/10.1017/RDC.2020.59

Huber, U., Markgraf, V., y Schäbitz, F. (2004). Geographical and temporal trends in late Quaternary fire histories of Fuego-Patagonia, South America. Quaternary Science Reviews, 23(9-10), 1079-1097.

Jans, M. M. E. (2008). Microbial bioerosion of bone - a review. En M. Wisshak y L. Tapanila (Eds.), Current Developments in Bioerosion (pp. 397-413). Springer.

Jans, M. M. E. (2014). Microscopic destruction of bone. En J. T. Pokines y S. A. Symes (Eds.), Manual of Forensic Taphonomy (pp. 19-36). CRC Press. 
Jans, M. M. E., Nielsen-Marsh, C. M., Smith, C. I., Collins, M., y Kars, H. (2004). Characterization of microbial attack on archaeological bone. Journal of Archaeological Science, 31, 87-95.

Kendall, C., Høier Eriksen, A.M., Kontopoulos, I., Collins, M., y Turner-Walker, G. (2018). Diagenesis of archaeological bone and tooth. Palaeogeography, Palaeoclimatology, Palaeoecology, 491, 21-37.

Koo, B. J., Adriano, D. C., Bolan, N. S., y Barton, C. D. (2005). Root exudates and microorganisms. En D. Hillel (Ed.), Encyclopedia of Soils in the Environment (pp. 421428). Elsevier Academic Press.

Langlais, M., y Morello, F. (2009). Estudio tecno-económico de la industria lítica de Cerro Castillo (provincia de Última Esperanza, Chile). Magallania, 37(1), 61-83.

Legoupil, D. (2009). La ocupación del alero de Cerro Castillo: un sitio residencial en un mirador panorámico. Magallania, 37(1), 47-60.

L'Heureux, G. L. (2003). Estudio comparativo de muestras arqueofaunísticas de guanaco (Lama guanicoe) de la cuenca superior del río Santa Cruz. Intersecciones en Antropología, 4, 75-85.

L'Heureux, G. L., y Borrazzo, K. (2016). Estudio longitudinal de un sitio en el bosque: Cancha Carrera 1 (Santa Cruz, Argentina). En Actas del XIX Congreso Nacional de Arqueología Argentina (pp. 111-118). Serie Monográfica y Didáctica 54. Facultad de Ciencias Naturales e Instituto Miguel Lillo, Universidad Nacional de Tucumán.

Linse, A. R. (1992). Is bone safe in a shell midden? En J.K. Stein (Ed.), Deciphering a Shell Midden (pp. 327-347). Academic Press.

Magnin, L. (2010). Distribuciones Arqueológicas en la Meseta Central de Santa Cruz. Implicancias para los Estudios de uso del Espacio y Movilidad de Sociedades Cazadoras Recolectoras (tesis doctoral inédita). Facultad de Ciencias Naturales y Museo, Universidad Nacional de La Plata, La Plata.

Mancini, M. V., Bamonte, F. P., y Sottile, G. D. (2011). Paleoecología y ocupaciones humanas durante el Holoceno en el área cordillerana y Patagonia extra-andina entre los $49^{\circ}$ y $51^{\circ} \mathrm{S}$, Santa Cruz (Argentina). En L.A. Borrero y K. Borrazzo (Eds.), Bosques, Montañas y Cazadores: Investigaciones Arqueológicas en Patagonia Meridional (pp. 37-59). CONICET-IMHICIHU.

Marchionni, L. (2013). Comparación de las Distintas Historias Tafonómicas en Conjuntos Zooarqueológicos Provenientes de la Meseta Central de la Provincia de Santa Cruz (tesis doctoral inédita). Facultad de Ciencias Naturales y Museo, Universidad Nacional de La Plata, La Plata.

Marchionni, L., García Añino, E., y Miotti, L. (2020). La fracturación de huesos largos durante el Holoceno medio en el Macizo del Deseado. Implicancias para el estudio del aprovechamiento de los guanacos. Comechingonia, Revista de Arqueología, 23(2), 81-110. http://doi. org/10.37603/2250.7728.v23.n2.27489

Martin, F. M. (1998). Madrigueras, dormideros y letrinas: aproximación a la tafonomía de zorros. En L.A. Borrero (Ed.), Arqueología de la Patagonia Meridional (Proyecto "Magallania") (pp. 73-96). Búsqueda de Ayllu.

Martin, F. M., y Borrero, L.A. (2010). Mundo subterráneo: tafonomía regional en el campo volcánico Pali-Aike, Santa Cruz, Argentina. En L.A. Borrero y J. Charlin (Eds.), Arqueología de Pali Aike y Cabo Vírgenes (Santa Cruz, Argentina) (pp. 55-80). CONICET-IMHICIHU.

Matteucci, S. D. (2018). Bosques patagónicos. En J. Morello, S.D. Matteucci, A.F. Rodríguez y M.E. Silva (Eds.), Ecorregiones y Complejos Ecosistémicos Argentinos (pp. 547-610) (2da ed.). FADU-GEPAMA.

Matsuoka, N. (1996). Soil moisture variability in relation to diurnal frost heaving on Japanese high mountain slopes. Permafrost and Periglacial Processes, 7, 139-151.

Miller, G. J. (1975). A study of cuts, grooves and other marks on recent fossil bone II: weathering cracks, fractures, splinters, and other similar natural phenomena. En E. Swanson (Ed.), Lithic Technology: Making and Using Stone Tools (pp. 211-226). Mouton.

Miotti, L., y Salemme, M. (2004). Poblamiento, movilidad y territorios entre las sociedades cazadoras-recolectoras de Patagonia: cambios desde la transición Pleistoceno/ Holoceno al Holoceno medio. Complutum, 15, 177-206.

Mondino, V., Pastorino, A., Mario, J., y Gallo, L.A. (2019). Variación altitudinal de caracteres fenológicos y crecimiento inicial en condiciones controladas entre poblaciones de Nothofagus pumilio provenientes del centro-oeste de Chubut, Argentina. Bosque, 40(1), 87-94. https:// dx.doi.org/10.4067/S0717-92002019000100087.

Moore, D. (1983). Flora of Tierra del Fuego. Anthony Nelson. Morales, N., Barrientos, G., y Belardi, J. B. (2017). Microscopic metrical characterization of bone weathering in a sample of modern guanaco (Lama guanicoe) from southern Patagonia, Argentina: implications for patterns of intraosseous differential preservation. Journal of Taphonomy, 15, 109-122.

Morales, N. S., Catella, L., Oliva, F., Sarmiento, P., y Barrientos, G. (2018). A SEM-based assessment of bioerosion in Late Holocene faunal bone assemblages from the southern pampas of Argentina. Journal of Archaeological Science: Reports, 18, 782-791. http://doi.org/10.1016/j.jasrep.2017.07.012

Moreno, P. I., Francois, J. P., Villa-Martínez, R. P., y Moy, C. M. (2009). Millenial-scale variability in the Southern Hemisphere westerly wind activity over the last 5000 years in SW Patagonia. Quaternary Science Reviews, 28, 25-38. 
Muñoz, S. (2017). Taphonomy of surface bone assemblages in coastal Patagonia: a case study zooarchaeology in the neotropics. En M. Mondini, S. Muñoz y P. Fernández (Eds.), Environmental Diversity and Human-Animal Interactions (pp. 123-136). Springer.

Muñoz, S., y Cruz, I. (2014). Estado actual de las investigaciones tafonómicas naturalistas en Punta Entrada y Monte León (Patagonia Meridional). Revista Chilena de Antropología, 29, 102-108.

Müller, A.H. (1963). Lehrbuch der Paläozoologie Band 1: Allgemeine Grundlagen. Gustav Fischer Verlag.

Nielsen-Marsh, C. M., y Hedges, R. (2000). Patterns of diagenesis in bone I: the effects of site environments. Journal of Archaeological Science, 27, 1139-1150.

Nielsen-Marsh, C. M., Smith, C. I., Jans, M. M. E., Nord, A., Kars, H., y Collins, M. (2007). Bone diagenesis in the european Holocene II: taphonomic and environmental considerations. Journal of Archaeological Science, 34, 1523-1531.

Nottingham, A. T., Fierer, N., Turner, B.L., Whitaker, J., Ostle, N.J., McNamara, N.P., Bardgett, R.D., Leff, J. W., Salinas, N., Silman, M. R., Kruuk, L. E. B., y Meir, P. (2018). Microbes follow Humboldt: temperature drives plant and soil microbial diversity patterns from the Amazon to the Andes. Ecology, 99, 2455-2466.

Oliva, G., González, L., Rial, P., y Livraghi, E. (2001). Áreas ecológicas de Santa Cruz y Tierra del Fuego. En P. Borrelli y G. Oliva (Eds.), Ganadería Ovina Sustentable en la Patagonia Austral. Tecnología de Manejo Extensivo (pp. 41-82). Instituto Nacional de Tecnología Agropecuaria (INTA).

Oyarzabal, M., Clavijo, J., Oakley, L., Biganzoli, F., Tognetti, P., Barberis, I., Maturo, H. M., Aragón, R., Campanello, P. I., Prado, D., Oesterheld, M., y León, R. J. C. (2018). Unidades de vegetación de la Argentina. Ecología Austral, 28, 040-063.

Pallo, C., y Ozán, I. (2014). Variaciones demográficas y climáticas durante el Holoceno tardío final en Magallania. Comechingonia Virtual, 7(1), 20-47.

Pallo, C., y Borrero, L.A. (2015). Arqueología de corredores boscosos en Patagonia Meridional: el caso del río Guillermo (SO de la provincia de Santa Cruz, Argentina). Intersecciones en Antropología, 16(2), 313-326.

Pallo, C., y Borrazzo, K. (2017). The archaeology of contact in southern Patagonia: some issues to be resolved in the southwestern forest. Arts and \& Humanities Open Access Journal, 1, 135-138.

Pallo, C., y Cirigliano, N. (2018). Prehistoric land use patterns in the Guillermo river basin (southwestern Patagonian forest, Argentina): a first look at the GIS dataset of surface lithic material. Annals of Archaeology, 1(1), 22-29.

Pallo, C., Cirigliano, N. A., Charlin, J. E., y Borrero, L. A. (2020). Tecnología lítica y uso del bosque patagónico entre cazadores recolectores: los casos de Puesto Aserradero y Laguna Cóndor (SO de Santa Cruz, Argentina). Revista del Museo de Antropología, 13(3), 307-320.

Pereyra, F. X. (2012). Suelos de la Argentina. SEGEMARAACS-GAEA.

Pérez Moreau, R.A. (1959). Reseña Botánica sobre el Lago Argentino. Publicación $N^{\circ} 1$. Instituto Nacional del Hielo Continental Patagónico.

Peri, P.L., y Monelos, L. (2006). Existencias de bosque nativo y forestación con salicáceas en la cuenca del río Coyle. En J.B. Belardi, F. Carballo Marina y S. Espinosa (Eds.), La Cuenca del Río Coyle. Estado Actual de las Investigaciones (pp. 233-247). UNPA.

Peri, P.L., y Ormaechea, S. (2013). Relevamiento de los Bosques Nativos de Nire (Nothofagus antarctica) en Santa Cruz: Base para su Conservación y Manejo. Ediciones INTA.

Peri, P. L., Martínez Pastur, G. J., Monelos, L., y Beroiz, M. (2013). La distribución más oriental de Nothofagus antarctica en el Río Gallegos (Santa Cruz). Anales del Instituto de la Patagonia, 41, 113-117.

Pettersson, M., y Bååth, E. (2003). Temperature-dependent changes in the soil bacterial community in limed and unlimed Soil. FEMS Microbiology Ecology, 45(1), 13-21.

Pike, A., Nielsen-Marsh, C. M., y Hedges, R. (2001). Modelling bone dissolution under different hydrological regimes. En R.A. Millard (Ed.), Archaeological Sciences 97. Proceedings of the Conference Held at the University of Durham (pp. 127-132). BAR, International Series 939, Archaeopress.

Pisano, E. (1977). Fitogeografía de Fuego-Patagonia chilena. I. Comunidades vegetales entre las latitudes $52^{\circ}$ y $56^{\circ}$ S. Anales del Instituto de la Patagonia, 8, 121-250.

Pisano, E. (1989-1990). Labilidad de los ecosistemas terrestres Fuego-Patagónicas. Anales del Instituto de la Patagonia, 19, 17-25.

Pokines, J.T., y Baker, J.E. (2014). Effects of burial environment on osseous remains. En J.T. Pokines y S.A. Symes (Eds.), Manual of Forensic Taphonomy (pp. 73-114). CRC Press.

Pokines, J. T., King, R. E., Graham, D. D., Costello, A. K., Adams, D. M., Pendray, J. M., Rao, K., y Siwek, D. (2016). The effects of experimental freeze-thaw cycles to bone as a component of subaerial weathering. Journal of Archaeological Science: Reports, 6, 594-602.

Prémoli, A. C., y Mathiasen, P. (2013). Todo lo que quiso saber sobre ella y no se atrevió a preguntar. Decálogo de la lenga. 
Desde la Patagonia Difundiendo Saberes, 10(16), 44-52. Roberts, S. J., Smith, C. I., Millard, A., y Collins, M. J. (2002). The taphonomy of cooked bone: characterizing boiling and its physico-chemical effects. Archaeometry, 44, 485-494.

Rosenblüth, B., Fuenzalida, H., y Aceituno, P. (1997). Recent temperate variations in southern South America. International Journal of Climatology, 17, 67-85.

Rubinos Pérez, A. (2003). Recopilación y análisis de las fechas de carbono-14 del norte de la provincia de Santa Cruz (Argentina). En A.M. Aguerre (Comp.), Arqueología y Paleoambiente en la Patagonia Santacruceña Argentina (pp. 1-25). Talleres Gráficos Offset.

San Román, M., y Morello, F. (2003). Nota sobre una excavación de sondeo en el alero de Cerro Castillo 1, Provincia de Última Esperanza, Magallanes (Chile). Magallania, 31, 139-147.

Skvarca, P. (2002). Importancia de los glaciares del hielo patagónico sur para el desarrollo regional. Geología y recursos naturales de Santa Cruz. Relatorio del XV Congreso Geológico Argentino (pp. 785-798). Buenos Aires.

Smith, C. I., Nielsen-Marsh, C. M., Jans, M. M. E., Arthur, P., Nord, A.G., y Collins, M. J. (2002). The strange case of Apigliano: early fossilisation of medieval bone in southern Italy. Archaeometry, 44, 405-416.

Smith, C. I., Nielsen-Marsh, C.M., Jans, M. M. E., y Collins, M. J. (2007). Bone diagenesis in the European Holocene I: patterns and mechanisms. Journal of Archaeological Science, 34, 1485-1493.

Soil Survey Staff. (1975). Soil Taxonomy. A Basic System of Soil Classification for Making and Interpreting Soil Surveys (1ra ed.). U.S. Department of Agriculture, Natural Resources Conservation Service.

Stuiver, M., Reimer, P. J., y Reimer, R. W. (2020). CALIB 8.2 [WWW program] disponible en http://calib.org.Google Scholar.

Tessone, A. (2010). Arqueología y Ecología Isotópica. Estudio de Isótopos Estables de Restos Humanos del Holoceno Tardio en Patagonia Meridional (tesis doctoral inédita). Facultad de Filosofía y Letras, Universidad de Buenos Aires, Buenos Aires.

Tessone, A., Fernández, P., Fernández, N., y De Nigris, M. (2020a). Variaciones $\delta^{13} \mathrm{C}$ y $\delta^{15} \mathrm{~N}$ en huemul (Hippocamelus bisulcus) durante el Holoceno en Cerro Casa de Piedra, Santa Cruz, Argentina. Implicancias para el estudio de su distribución pasada. Intersecciones en Antropología, 21(1), 5-16.

Tessone, A., Miotti, L., Marchionni, L., Hermo, D., y Mosquera, B. (2020b). $\delta^{13} \mathrm{C}$ y $\delta^{15} \mathrm{~N}$ de fauna proveniente de sitios arqueológicos del Macizo del Deseado, Santa Cruz, Argentina. Magallania, 48(1), 123-140.

Trueman, C. N. (1999). Rare earth element geochemistry and taphonomy of terrestrial vertebrate assemblages. Palaios, 14(6), 555-568.

Trueman, C.N., y Tuross, N. (2002). Trace elements in recent and fossil bone apatite. En M. J. Kohn, J. Rakovan y J.M. Hughes (Eds.), Phosphates: Geochemical, Geobiological, and Materials Importance (pp. 489-521). Reviews in Mineralogy and Geochemistry 48. Mineralogical Society of America.

Turner-Walker, G. (2012). Early bioerosion in skeletal tissues: persistence through deep time. Neues Jahrbuch für Geologie und Paläontologie, 265, 165-183.

Turner-Walker, G. (2019). Light at the end of the tunnels? The origins of microbial bioerosion in mineralised collagen. Palaeogeography, Palaeoclimatology, Palaeoecology, 529, 24-38.

Turner-Walker, G., y Parry, T. V. (1995). The tensile strength of archaeological bone. Journal of Archaeological Science, 22, 185-191.

Turner-Walker, G., y Jans, M.C. (2008). Reconstructing taphonomic histories using histological analysis. Palaeogeography, Palaeoclimatology, Palaeoecology, 266, 227-235.

Turner-Walker, G., Nielsen-Marsh, C. M., Syversen, U., Kars, H., y Collins, M. J. (2002). Submicron spongiform porosity is the major ultra-structural alteration occurring in archaeological bone. International Journal of Osteoarchaeology, 12, 407-414.

van Klinken, G.J. (1999). Bone collagen quality indicators for palaeodietary and radiocarbon measurements. Journal of Archaeological Science, 26, 687-695.

Villalba, R., Lara, A., Boninsegna, J., Masiokas, M., Delgado, S., Aravena, J. C., Roig, F., Schmelter, A., Wolodarsky, A., y Ripalta, A. (2003). Large-scale temperature changes across the southern Andes: 20th-century variations in the context of the past 400 years. Climatic Change, 59, 177-232.

Villegas, D.C. (2004). Suelos, Geoformas y Materiales Originarios entre los Lagos San Martín y Viedma, Prov. de Santa Cruz (tesis doctoral inédita). Facultad de Ciencias Exactas y Naturales, Universidad de Buenos Aires.

Villegas, D. C., Pereyra, F. X., y Ferrer, J. A. (2007). Suelos, factores de formación y procesos pedogenéticos en el centro oeste de la provincia de Santa Cruz. Revista de la Asociación Geológica Argentina, 62, 366-374.

Von Endt, D. W., y Ortner, D.J. (1984). Experimental effects of bone size and temperature on bone diagenesis. Journal of Archaeological Science, 11, 247-253.

Wheeler, A., y Jones, A. (1989). Fishes. Cambridge University Press.

Zilio, L., Tessone, A., y Hammond, H. (2018). Stable isotope ecology and human palaeodiet in the northern coast of Santa Cruz (Argentine Patagonia). International Journal of Osteoarchaeology, 28(3), 305-317. 